Portland State University

PDXScholar

5-8-1991

\title{
Assessing the Intercultural Sensitivity of American Expatriates in Kuwait
}

Deborah Ann Turner

Portland State University

Follow this and additional works at: https://pdxscholar.library.pdx.edu/open_access_etds

Part of the International and Intercultural Communication Commons

Let us know how access to this document benefits you.

\section{Recommended Citation}

Turner, Deborah Ann, "Assessing the Intercultural Sensitivity of American Expatriates in Kuwait" (1991). Dissertations and Theses. Paper 4288.

https://doi.org/10.15760/etd.6171

This Thesis is brought to you for free and open access. It has been accepted for inclusion in Dissertations and Theses by an authorized administrator of PDXScholar. Please contact us if we can make this document more accessible: pdxscholar@pdx.edu. 
AN ABSTRACT OF THE THESIS OF Deborah Ann Turner for the Master of Science in Speech Communication presented May 8, 1991.

Title: Assessing the Intercultural Sensitivity of American Expatriates in Kuwait.

APPROVED BY THE MEMBERS OF THE THESIS COMMITTEE:
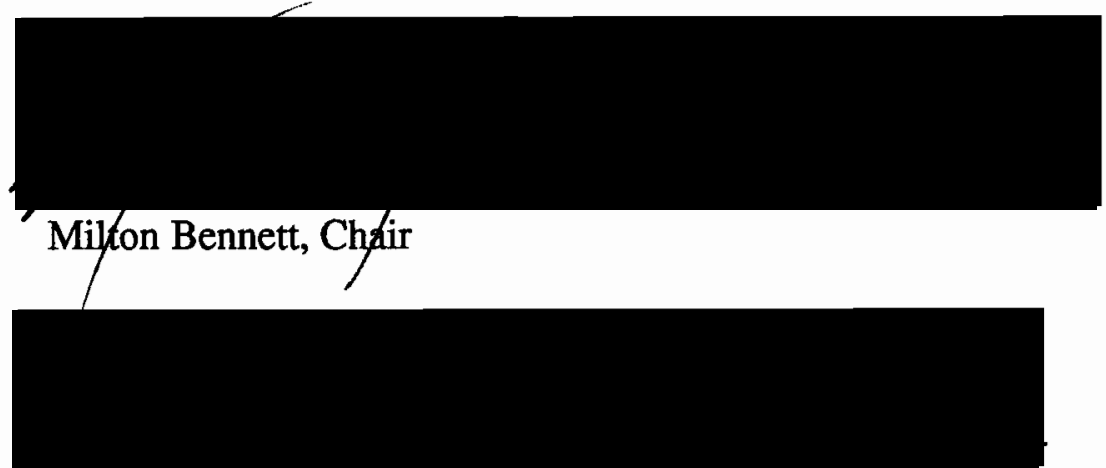

Stephen Kosokoff

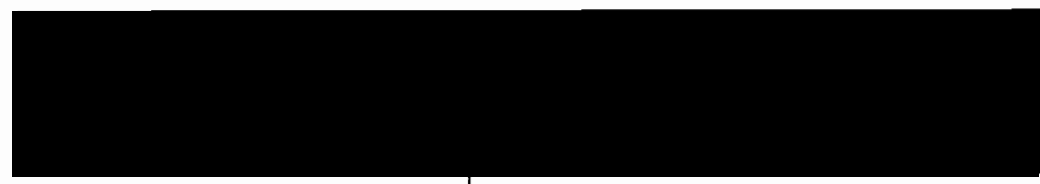

Devorah Lieberman

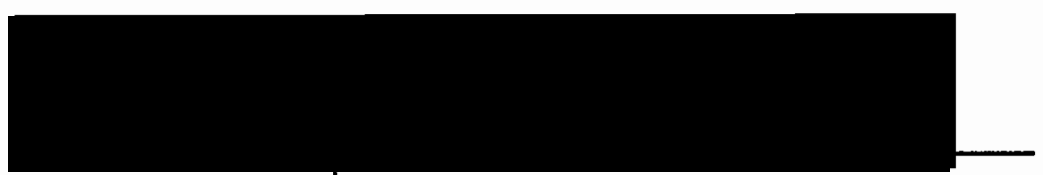

Kimberley Brown

The purpose of this study is to apply a developmental model of intercultural sensitivity to a group of people in an intercultural setting and discover whether or not the model is descriptive. The data collected are also used to determine whether or not the coping mechanisms employed by the sojourners are developmental in terms of this model of intercultural sensitivity. 
The population for this study was the American community of Kuwait in 1989 and 1990. Fifteen subjects, all of whom had lived in Kuwait at least two years, were interviewed in Kuwait. The model used is Bennett's (1984) Developmental Model of Intercultural Sensitivity. This model consists of six levels of sensitivity, including the three ethnocentric levels of Denial, Defense and Minimization, and the three ethnorelative levels of Acceptance, Adaptation and Integration.

This is an exploratory study that utilizes a descriptive method of data collection and a qualitative method of data analysis. The in-depth interview is used as a research gathering tool. The initial exploratory phase of the research resulted in the development of the interview schedule. This was derived from a review of the literature of intercultural adjustment. The five major topic areas which emerged were (a) attitude toward difference, (b) interaction, (c) comunication, (d) stress management, and (e) satisfaction. The questions were based on the most commonly agreed upon factors of adjustment and were designed to elicit responses which could be coded as representative of a particular level of intercultural sensitivity according to the model being examined.

The coding of responses followed an analytical scheme developed by the researcher. The responses of each interview subject are analyzed and presented in the form of interview extracts labeled with the level of sensitivity. A percent of responses given at each level is the result.

In the second part of the study, the purpose is to determine the developmental effectiveness of coping mechanisms employed by the sojourners. The themes which emerged from the data are arranged acording to their developmental possibilities. Actions taken which encourage movement on the continuum of intercultural sensitivity are labeled developmental. Those which inhibit it are labeled nondevelopmental.

The findings support the use of the model as a descriptive tool. The responses of the subjects are consistent; the majority of each individual's responses falls into one 
category of intercultural sensitivity. The examination of coping mechanisms reveals further consistency. The individuals labeled as ethnorelative account for a larger share of the developmental responses than their numbers would indicate.

The results are generally supportive of the literature. The attitude toward difference and satisfaction with interactions discriminated between those who were labeled as ethnorelative and those who were not.

The results concerning satisfaction are perhaps the most surprising. While 11 subjects were categorized as being in Defense (an ethnocentric state characterized by negative evaluations of difference), all 15 subjects reported finding their experience satisfactory overall.

Their length of time in Kuwait implies that their hosts were reasonably satisfied with their performance. This suggests that intercultural sensitivity is not as integral a part of intercultural effectiveness as previously presumed. Those who were ethnorelative described a much more positive experience, but those who were not had also found the experience rewarding.

A potential application of this study is the use of the model in intercultural training. The model does describe individuals and, used with a clear diagnostic tool, would be helpful in the development of appropriate activities to promote an increase in intercultural sensitivity. It also suggests, however, that situational variables must be considered when determining the importance of advanced levels of sensitivity in various intercultural settings. 


\title{
ASSESSING THE INTERCULTURAL \\ SENSITIVITY OF AMERICAN \\ EXPATRIATES IN KUWAIT
}

by

DEBORAH ANN TURNER

A thesis submitted in partial fulfillment of the requirement for the degree of

\author{
MASTER OF SCIENCE \\ in \\ SPEECH COMMUNICATION
}

Portland State University

1991 


\section{TO THE OFFICE OF GRADUATE STUDIES:}

The members of the Committee approve the thesis of Deborah Ann Turner presented May 8, 1991.
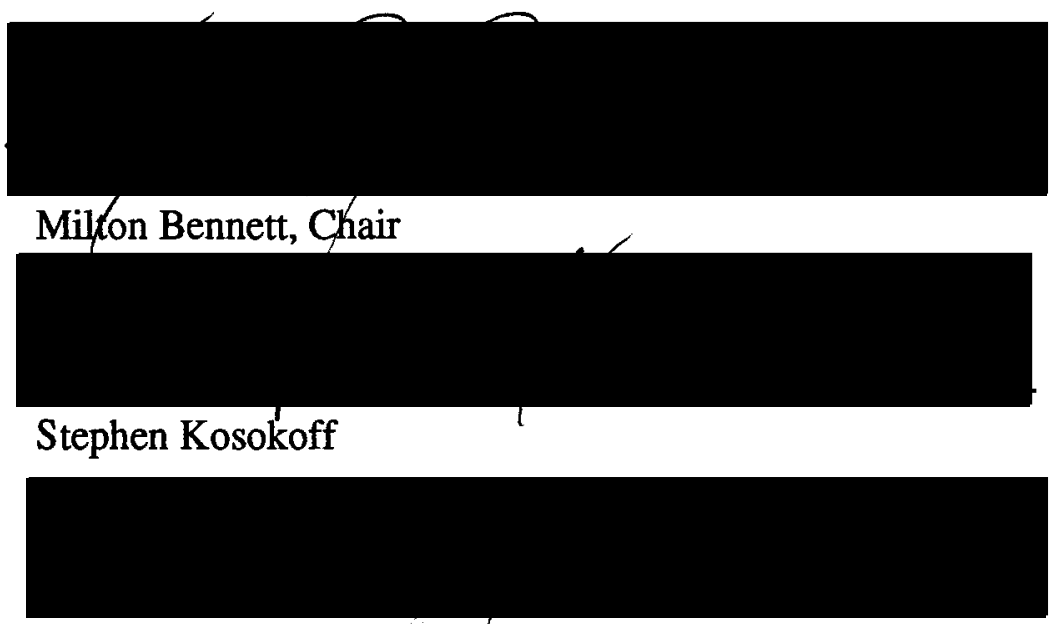

Devorah Lieberman

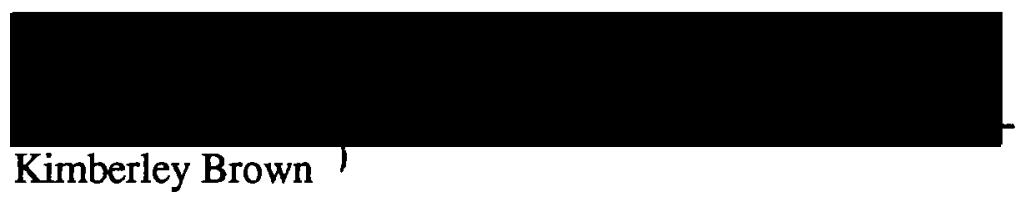

APPROVED:

Theodore G. Grove, Chair, Department of Speech Communication

C. William Savery, Interim Vice Provost for Graduate Studies and Research 


\section{DEDICATION}

This thesis is dedicated to the people of Kuwait, particularly my friends and students who shared their perspectives and parts of their lives with me, making my five years in their country so special. It is my hope that they will be able to take advantage of the best of many worlds, creating a new Kuwait that lives up to its fullest potential. 


\section{ACKNOWLEDGEMENTS}

There are many people whose assistance was invaluable to me and, without whom this thesis would never have been completed. First and foremost, I would like to express my gratitude to Milton Bennett, my advisor, whose encouragement and support despite unusual circumstances prevented me from giving up. His enthusiasm and helpful suggestions were a continuing inspiration throughout the long process.

I would also like to thank Stephen Kosokoff and Devorah Lieberman for serving on my committee and for being understanding of the difficulties along the way. In addition, I would like to express my appreciation to LaRay Barna who was instrumental in my pursuit of this degree. I would like to thank her for the understanding ear and thoughtful attention she gave.

I would like to say particular thanks to the 15 Americans who gave of their time and shared their experiences with me in these interviews. It is not my intention to pass judgment and I apologize if I misinterpreted any of their comments, attitudes and feelings.

I am indebted to my husband, family and friends who provided encouragement, positive support, baby-sitting and the occasional necessary prod to keep the project moving. In particular, I would like to thank Ceil, whose expertise with the computer has been a lifesaver this last month; Doug, Veena and Androulla, who were sounding boards and readers in Kuwait; my colleagues and supervisors at the Kuwait Petroleum Training Centre, who left me alone with my headphones and tapes whenever possible; and finally, my Arab friends of various nationalities, Maya, Safa, Tahsin, Abu Mahmoud, Ahmad, Adel, Daoud, Abbas, Jamal, and Bader, whose insights into a new way of thinking led me to whatever understanding of their complex and fascinating culture I now possess. It has certainly not been easy, but it has never been boring. Many thanks to all of you. 


\section{TABLE OF CONTENTS}

\section{PAGE}

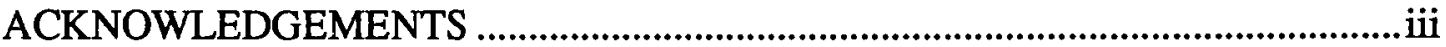

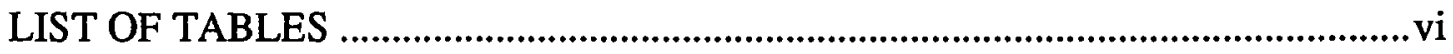

LIST OF FIGURES ..................................................................................................

\section{CHAPTER}

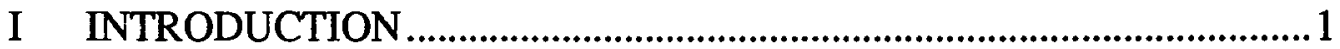

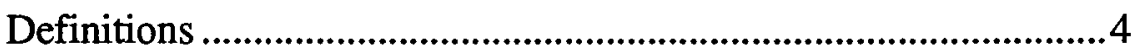

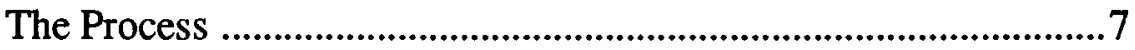

II REVIEW OF THE LITERATURE .......................................................9

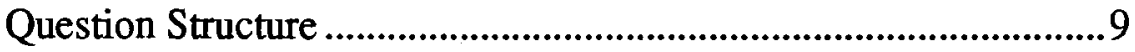

Review of the Literature Related to Topic Areas.......................... 11

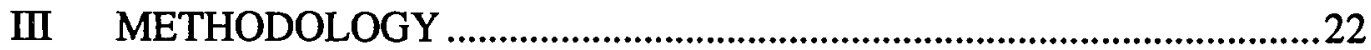

General Approach ...................................................................22

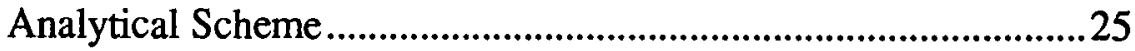

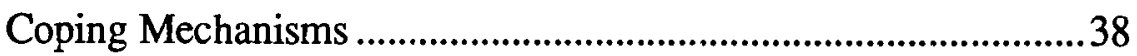

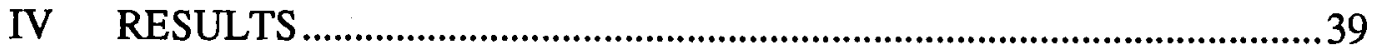

Summary of Questions ...............................................................39

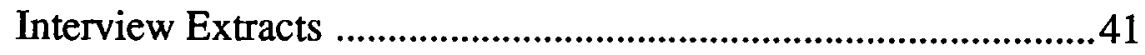

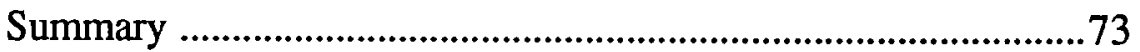

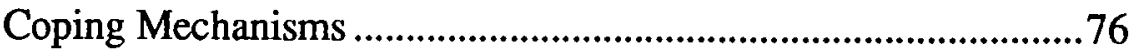


$\mathrm{V}$ DISCUSSION AND INTERPRETATION ................................................. 84

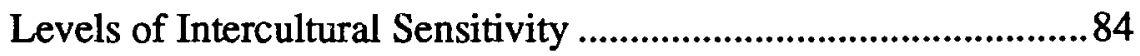

Coping Mechanisms .......................................................................103

Summary ...................................................................................104

VI LIMITATIONS, SUGGESTIONS FOR FURTHER RESEARCH, AND PRACTICAL APPLICATIONS .................................107

Effectiveness of Method...............................................................107

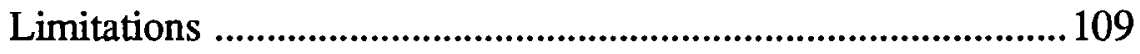

Directions for Future Research ...................................................111

Practical Applications .........................................................................113

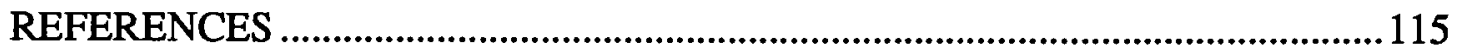

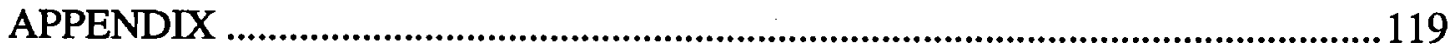




\section{LIST OF TABLES}

TABLE

PAGE

I A Developmental Model of Intercultural Sensitivity ................................5

II The Subjects' Levels of Intercultural Sensitivity ....................................74

III Developmental and Nondevelopmental Coping Mechanisms .................8 83

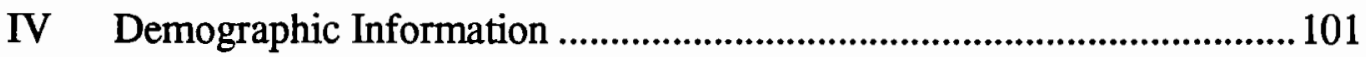




\section{LIST OF FIGURES}

FIGURE

PAGE

1 Experience of Difference ....................................................................6

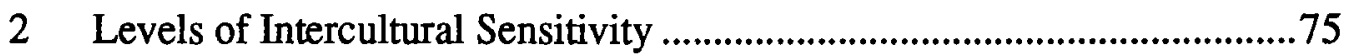




\section{CHAPTER I}

\section{INTRODUCTION}

Each year, thousands of Americans go abroad in a variety of functions. They may be managers in multinational corporations, technical advisors, teachers, students or military personnel. The success of these ventures varies widely, both from the perspective of the sojourner and the perspective of the host. Successful ventures result in a satisfied sojourner, one who has accomplished personal and professional goals, and satisfied hosts, who have gotten the work or product desired. In this scenario, both sojourner and host complete their business with feelings of mutual respect. Many interactions lead to few if any of these results, however, and unsuccessful ventures can be costly in both monetary and human terms. Consequently, many studies have been done on these groups of sojourners to determine the factors involved in their successful adjustment to the foreign environment.

Some researchers have seen adjustment as a linear progression, with adjustment occurring in the final stage when the sojourner achieves cultural awareness and acceptance. Oberg (1960), in his discussion of culture shock, posited four stages of adjustment moving from elation to crisis to recovery to the final stage of adjustment, when the sojourner accepts the host culture. Adler (1975) viewed adjustment as a transitional experience, "a movement from a state of low self and cultural awareness to a state of high self and cultural awareness" (p. 15).

Other studies have resulted in a list of personal characteristics or found in adjusted sojourners. In a review of the literature on successful sojourners, Kealey and Ruben (1983) found a "total consensus on six criteria: empathy, respect, interest in local culture, flexibility, tolerance and technical skill" (p. 165). Gudykunst, Wiseman, and 
Hammer (1977) proposed a similar "third culture perspective" which is central to effective intercultural interactions. It consists of open-mindedness, empathy, accurate perceptions of similarities and differences in cultures, nonjudgemental attitudes, astute observations of one's own and others' behavior, the ability to interact with host nationals, and little ethnocentrism.

While few would disagree with the desirability of these qualities, a problem with these approaches is the implication that culturally insensitive people are not adjusted to the environment. In fact, many types of adjustment are possible, but not all of them are conducive to effective intercultural communication. "It is quite possible to be successful in terms of adjustment and unsuccessful for the perspective of global effectiveness" (Kealey and Ruben, 1983, p. 167). One may easily develop a style of coping that is comfortable but that does not enhance intercultural learning or accomplishment of the task.

In recognition of this possibility, others have discussed adjustment in terms of the varying patterns or strategies of dealing with the new environment. Sewell and Davidson (1956) found four patterns of adjustment and labeled them (a) detached observers, (b) promoters, (c) enthusiastic participants, and (d) settlers. Useem (1966) described American wives in India as (a) copers, (b) cautious, (c) supporters, and (d) fumblers. More recently, Gudykunst and Hammer (1987) have described strategies of adaptation in terms of uncertainty reduction. Different patterns emerge ranging from high uncertainty coupled with high anxiety indicating a lack of adaptation, to low uncertainty and low anxiety indicating total adaptation. The other two patterns (high uncertainty/low anxiety or low uncertainty/high anxiety) reflect recognition that adaptation may take many forms. Not all those who adapt understand the culture (high uncertainty/low anxiety) or feel comfortable in it (low uncertainty/high anxiety). An advantage of these perspectives is the recognition that there are a variety of coping mechanisms people adopt when confronted with the new culture. 
Bennett (1986) endeavors to get at the essence of these by discussing intercultural sensitivity as "the meaning which people attach to cultural difference and to the varying kind of experience that accompanies different meaning attributions" (p. 5). When viewed as a developmental continuum, a low level of intercultural sensitivity reflects an ethnocentric viewpoint - the "tendency to identify with our in-group (e.g., ethnic or racial group, culture) and to evaluate out-groups and their members according to its standards" (Gudykunst and Kim, 1984, p. 92). The "meaning attributions" then are derived from our own cultural framework. Moving from ethnocentrism to ethnorelativism, or a higher level of intercultural sensitivity, the intercultural learner develops the qualities noted by Kealey and Ruben (1983) including empathy, respect, interest in local culture, flexibility, and tolerance, and those included in the aforementioned third culture perspective of Gudykunst, Wiseman and Hammer (1977). The "meaning attributions" here are culturally relative, derived from another cultural framework.

As such, intercultural sensitivity is at the core of descriptions of adjustment (Benson, 1978; Church, 1982), intercultural effectiveness (Kealey and Ruben, 1983), intercultural competence (Dinges, 1983; Martin, 1987) and intercultural learning (Hoopes, 1981).

Bennett's (1986) model of intercultural sensitivity is closely related to Hoopes' (1981) model of intercultural learning. Hoopes' sequence begins with ethnocentrism, which is followed by awareness, understanding, acceptance/respect, appreciation/valuing, selective adoption and, finally, assimilation-adaptation-biculturalism-multiculturalism. His model provides a framework for development — for understanding intercultural learning through movement on the continuum.

Bennett's model serves a similar purpose. It is intended, however, not merely to describe, but to serve as a diagnostic tool when determining the needs of intercultural learners. It provides descriptions of each level and stage, ways to encourage development, and potential problems that may be encountered (Bennett, 1986). It provides a framework for 
what Dinges (1983) called "dynamic learning" — increasing awareness and expanding understanding as a result of the dynamic interaction of the person and the environment.

This paper will presume that intercultural sensitivity as defined is generally accepted as a desired outcome of the sojourn experience, but that an ability to cope with the environment does not necessarily imply the development of intercultural sensitivity. The questions for research, then, are these:

1) Does Bennett's (1986) Developmental Model of Intercultural Sensitivity allow us to describe sojourners' responses to a variety of topics as indicative of a particular stage of development?

2) Are coping strategies which could be labeled as developmental according to Bennett's (1986) model more likely to be reported by sojourners at a higher developmental stage than by sojourners at a lower developmental stage?

\section{DEFINITIONS}

The model is comprised of six stages: (a) denial; (b) defense; (c) minimization; (d) acceptance; (e) adaptation; and (f) integration. Denial implies the denial of difference caused by isolation from it or rejection of it. Defense includes denigration of difference, feelings of superiority, or reversal - denigration of one's own cultural background. Minimization is an attempt to see only similarities - the view that we are basically all alike, either because of our physical being or because of transcendental notions of all being one. The level of acceptance is the first ethnorelative stage. Its two categories are behavioral relativism, which is the respect for behavior differences, and value relativism, which is the respect for value differences. The next phase, adaptation, indicates an ability to shift one's frame of reference. The final stage, integration, describes a process of integrating varied cultural contexts into one's sense of self. These stages will be discussed in much greater detail in Chapter III, in relation to the analytical scheme. Table I and Figure 1 (Bennett, 1986) on the following pages clarify the meanings of the terms and the levels of the continuum. 
TABLE I

\section{A DEVELOPMENTAL MODEL OF \\ INTERCULTURAL SENSITIVITY}

\section{ETHNOCENTRIC STATES}

I. Denial of Difference. No recognition of cultural difference because of isolation or intentional separation. Attribution of deficiency in intelligence or personality to culturally deviant behavior. Tendency to dehumanize outsiders.

II. Defense against Difference. Recognition of cultural difference coupled with negative evaluation of most variations from native culture - the greater the difference, the more negative the evaluation. Evolutionary view of cultural development with native culture at the acme. A tendency towards social/cultural proselytizing of "underdeveloped" cultures.

Reversal. Tendency to see another culture as superior while maligning one's own.

III. Minimization of Difference. Recognition and acceptance of superficial cultural differences such as eating customs, etc., while holding that all human beings are essentially the same. Emphasis on the similarity of people and commonality of basic values. Tendency to define the basis of commonality in ethnocentric terms (ie. everyone is essentially like us).

Physical Universalism. Emphasis on commonality of human beings in terms of physiological similarity.

Transcendent Universalism. Emphasis on commonality of human beings as subordinate to a particular supernatural being, religion, or social philosophy.

\section{ETHNORELATIVE STATES}

IV.Acceptance of Difference. Recognition and appreciation of cultural differences in behavior and values. Acceptance of cultural differences as viable alternative solutions to the organization of human existence. Cultural relativity.

V. Adaptation to Difference. The development of communication skills that enable intercultural communication. Effective use of empathy, or frame of reference shifting, to understand and be understood across cultural boundaries.

VI. Integration of Difference. The internalization of bi-cultural or multicultural frames of reference. Maintaining a definition of identity that is "marginal" to any particular culture.

(Adapted from Bennett, 1986, p. 32) 


\section{EXPERIENCE OF DIFFERENCE}

DEVELOPMENT OF INTERCULTURAL SENSITIVITY

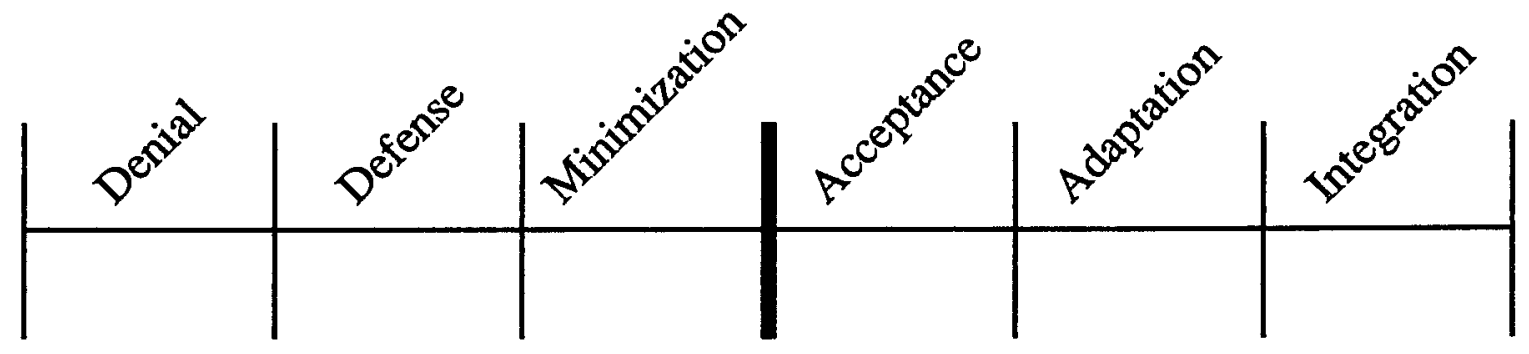

ETHNOCENTRIC

STAGES

ETHNORELATIVE

STAGES

Figure 1. Experience of difference. Source: Bennett, 1986. 
For the purposes of this paper, a sojourner will be defined as a relatively short term visitor to a new culture where permanent settlement is not the purpose of the sojourn (Church, 1982, p. 540). Coping mechanisms will be defined as behaviors or activities which enable the sojourner to tolerate the ambiguous or stressful situations frequently encountered while living abroad. Developmental adaptation is behavior that encourages movement on the continuum of intercultural sensitivity. There is potential for confusion in the use of the terms "adjustment" and "adaptation." They are used interchangeably in the literature and will be used as such in their general sense by the author. The contexts in which they are applied make it clear, however, that it is their general usage, not specific, as in the model, which is intended.

\section{THE PROCESS}

The research undertaken here will provide information about Americans in an intercultural setting. While there is considerable literature on the subject, there is little empirical substantiation. And while there are many common themes and ideas, there is a lack of agreement on terminology. This thesis synthesizes the varied terminology and relates it to Bennett's (1986) Developmental Model of Intercultural Sensitivity and applies this model in the field. It sheds light on the usefulness of such a model and operationalizes the first research question with the foloowing questions:

1) Are responses consistent enough to justify the use of Bennett's Developmental Model as a research tool?

2) Does the model deserve a more systematic study?

This thesis is descriptive. Its aim is to describe a process (the development of intercultural sensitivity) that was underway and the "noticeable, within awareness" effects on those in that process (Tucker, 1981, p. 90). It will describe events and the sojourners' reactions to those events in terms of the framework established - 
Bennett's (1986) Model of Intercultural Sensitivity.

Fifteen interviews were conducted. The interviewees were drawn from the American community, of which the author was a member, in Kuwait during the years of 1989 and 1990. All of those interviewed had lived in Kuwait at least two years, some much longer. They were all very interested in discussing their experiences and they willingly shared their impressions, understandings and misunderstandings.

The interview schedule, derived from a review of the literature, was open-ended, allowing the interviewee to respond in a manner appropriate to his or her experience, and allowing the interviewer to adapt the questions to the individual. The interview schedule consisted of a series of questions arranged in five topic areas:
1) Attitude toward Difference
2) Interaction
3) Communication Skills
4) Stress Management
5) Satisfaction

The above categories were derived from various treatments of intercultural adjustment and will be explained in detail in the following chapter.

Chapter II contains the review of the literature on cross cultural adjustment which led to the development of the interview schedule. Chapter III discusses the methodology used in conducting the study and contains the detailed analytical scheme which was used in coding the responses. Chapter IV includes the interview extracts with the coded responses as they relate to Question 1 and a summary of the results which relate to Question 2. The discussion of the results appears in Chapter V. This chapter analyzes data concerning the research questions and relates these findings to the literature. The limitations, suggestions, and applications are described in Chapter VI. 


\section{CHAPTER II}

\section{REVIEW OF THE LITERATURE}

This chapter will review the literature on intercultural adjustment and describe the manner in which the specific interview schedule (see Appendix) was developed.

\section{QUESTION STRUCTURE}

The questions are designed so that it is possible for the answer to each question to reflect the interviewee's level of sensitivity, whether ethnocentric or ethnorelative. This is done through the use of the Description - Interpretation - Evaluation format (M. Bennett and J. Bennett, 1977). According to Gudykunst and Kim (1984), an effective communicator can distinguish between the three processes and thereby communicate with fewer misunderstandings.

Description asks for an actual report of what has been observed. It requires a minimum of distortion and is deceptively difficult to perform. Minimally distorted description is difficult because description is based on subjective reality - an individual's perceptions, which are largely learned. According to Singer (1985), "Not only the languages he speaks and the way in which he thinks, but even what he sees, hears, tastes, touches, and smells are conditioned by the cultures in which he has been raised (p. 63). In the case of two very different cultures (American and Kuwaiti), simple description is made more difficult because fewer perceptions are shared. For example, as Nydell (1987) points out in a discussion on different communicative styles, "Arabs talk a lot, repeat themselves, shout when excited and make extensive use of gestures....Foreigners sometimes wonder if they are involved in a discussion or an argument" (p. 104). An aware 
communicator would describe the speech as "loud," leaving room for alternative interpretations. One lacking awareness leaps immediately to "angry," thereby opening the door to further misunderstanding.

Interpretation asks what we think about what we see and hear. It is an element of the cognitive component - how information is processed — of Gudykunst and Kim's (1984) successful intercultural communication. What we know or think we know about another culture has direct impact on our interpretations. Difference based interpretations are necessary for progress into the ethnorelative stages. While they may not always be accurate, interpretations which allow for different "realities" should lead to fewer negative evaluations.

Evaluation is the positive or negative judgment concerning the social significance we attribute to behavior. This is the level most commonly discussed by intercultural communication writers. Nonjudgementalness is one aspect of Gudykunst, Wiseman and Hammer's (1977) third culture perspective and is a successful communication behavior as discussed by Ruben (1977). Barna (1976) says that the tendency to evaluate without empathy is a "stumbling block" to effective intercultural communication. Evaluation is the affective component, involving the sentiment or emotion attached to the information processed, in Gudykunst and Kim's (1984) discussion of successful communication.

Effective communication does not stop here however. Dinges (1983) emphasizes the importance of performance when discussing intercultural competence and suggests that intercultural training might be more effective if it concerned "itself more with producing defined behavioral outcomes instead of operating on the assumption that providing insight, awareness, and understanding of important underlying cultural assumptions bring about enhanced performance on their own" (p. 194). Bochner (1986) agrees, saying that, "Interpersonal difficulties across cultural boundaries stem from the participants not possessing the requisite social skills," (p. 241) not from their lack of empathy. Gudykunst 
and $\mathrm{Kim}$ (1984) list a behavioral component, in addition to cognitive and affective components, of successful intercultural communication. This refers to the ability to enact proper behaviors. They say that "ultimately what is critical is whether they carry out the appropriate role performance in the host society" (p. 212). Ruben's (1977) discussion of intercultural effectiveness has behavioral aspects, calling not just for empathy, but for a display of empathy and display of respect.

While it is beyond the scope of this study to measure the actual intercultural effectiveness of the sojourner's behavior, a self-report of actions taken and the reasons for those actions is expected to indicate levels of intercultural sensitivity.

\section{REVIEW OF THE LITERATURE RELATED TO TOPIC AREAS}

\section{Demographic Data}

According to Church (1982), many variables may affect overseas adjustment. Among these are age, sex, and occupation.

Language. In addition, several studies cited by Kealey and Ruben (1983) cite language ability as a component of cross-cultural success. However, as English is so widely spoken in Kuwait, this may or may not be a factor here. In this case, a demonstrated interest in Arabic may contribute to overall effectiveness. Rather than mentioning language ability, Kealey and Ruben (1983) use "interest in the local language, such as modes of greetings or salutations" as an indicator of intercultural interaction, a critical aspect of overseas effectiveness. Gudykunst and Kim (1984) agree that fluency may not be necessary, but efforts to communicate in the language will usually be appreciated and result in more effective communication. Benson (1978) cites a positive correlation of language ability and overseas adaptation, but concludes that, apparently, adapted people learn the language, but personnel who learn the language may or may not adapt. 
Previous overseas experience. Much attention to previous overseas experience seems unwarranted. Stoner, Aram and Rubin (1972) found that it was not related to performance. Dinges (1983) described the expectation that it was relevant as the exposure - experience - expertise fallacy. Nonetheless, Church (1982) found that many selectors assumed that previous experience would indicate the likelihood of past and future adjustment. However, as Kelly (1963) says, "It is not what happens around him that makes a man experienced, it is the success in construing and reconstruing of what happens...that enriches the experience of life" (p. 12). Given the above research, previous experience is not expected to differentiate between ethnocentric and ethnorelative sojourners.

Predeparture expectations. Knowledge of Kuwait before arrival is included in demographic information. A set of realistic predeparture expectations was one of three predictors of overseas effectiveness (Kealey and Ruben, 1983). Stoner, Aram, and Rubin (1972) found that accurate initial expectations of the work situation were of great importance in predicting future success. Just as realistic expectations can be a great help, so can unrealistic predeparture expectations in terms of preconceptions or stereotypes be a "stumbling block." According to Barna (1976), "Knowing what to expect too often blinds the observer to all but what is confirmatory to his image or preconception. Contradictory evidence is likely to be treated as an exception" (p. 293).

Stereotypes of Arabs abound and are often negative. According to Nader (1977), the present image of the Arab most commonly held by Americans is one who is "cruel, weak and decadent" (p. 173). Slade (1987) says that "Arabs remain one of the few ethnic groups who can still be slandered with impunity in America" (p. 143). Face to face interaction may confound these preconceptions, but the outcome of the ambiguity is still often the statement, "He's not like the rest of them." 
Length of time in Kuwait. People who had lived in Kuwait less than two years were not part of the sample in order to exclude those who might still be in "transition shock" (J. Bennett, 1977). In addition to the possibility of transition shock, different lengths of time spent on the sojoum result in different types of experiences. According to Brein and David (1971), sojourns of two or three years have qualities which distinguish them from shorter visits. It is thought that in the longer period of time, individuals would find it necessary to interact with the new culture, and at least observe, if not learn, new ways of behaving. Since the focus of this study was the subjects' intercultural experiences, time for these interactions to take place and to be construed was necessary.

A large group of Americans residing in Kuwait was excluded from this study. These were the women married to Kuwaitis or other Arabs. Since many of them intended to live permanently in the Arab world, the researcher recognized the possibility of different motivations and different goals for adjustment, in addition to very different intercultural interactions.

\section{Attitude toward Difference}

Bennett (1986) sees the attitude toward difference as the major factor "in a learner's successful acquisition of the intercultural perspective" (p. 5). It is his assumption that perceptions of cultural difference vary in relation to levels of sensitivity and that development of an intercultural perspective depends on the acceptance of cultural relativity.

The importance of cultural difference is supported in the literature on adjustment. Benson (1978) synthesized current writings on adjustment and one of his dimensions of overseas adaptation is "attitudes" which includes tolerance of and respect for host nationals. Gudykunst, Wiseman and Hammer's (1977) study of cross-cultural attitude generated the "third culture perspective" which specifically referred to the perception of difference in two of seven characteristics describing individuals who have developed this perspective. Such individuals "accurately perceive differences and similarities between the host 
culture and their own [and] are relatively astute noncritical observers of their own behavior and ...others"' (p. 424). They also discuss open-mindedness, a quality also noted by Kealey and Ruben (1983) in their description of intercultural effectiveness. Openmindedness reflects a willingness to both perceive difference and be nonjudgemental in evaluating it - the core of developing the intercultural perspective. Martin's (1987) factors of intercultural competence go further, including behavioral as well as cognitive and affective components. Interculturally competent sojourners are able not only to identify differences, but to solve problems arising from them.

Arab and American cultural differences. American sojourners encounter many differences when experiencing an Arab culture. While there are many basic similarities in the various Arab cultures, an important caution is one given by Arab authors in reference to the dangers inherent in any discussion of Arab society. In a panel discussion, Said (1977) stated, "I should use the phrase Arab society with quotation marks around it because I am not sure which Arab society we are talking about" (p. 182).

While the research in this paper is primarily focused on Kuwait and Kuwaitis, American sojourners had contact with Arabs from all over the Arab world. Furthermore, there is little research done on Kuwaiti culture in particular. Therefore, when specific Arab/American cultural differences are discussed, it will be based on many sources who agree that the following are generally true for Arab cultures: (Adelman and Lustig, 1981; Hall, 1979; Lamb, 1987; Lee, 1980; Marr, 1978; Nydell, 1987; Shouby, 1951; Yousef, 1974).

1. Arabs are group-oriented and mutually dependent.

2. Face and status are of great importance.

3. There are distinctly different status positions for men and women.

4. Personal relations are very important.

5. There is a strong sense of public/private self. 
6. Arabs are generally flexible about time.

7. Islam is of paramount importance in daily life.

That this represents a great variance from traditional American values is supported by the contrasting American cultural values listed below:

1. Americans are individualistic, self-reliant and oriented toward competition.

2. Americans value informality and equality in social situations.

3. Time is generally viewed in a rigid, linear sense.

4. Americans have objective impersonal relations.

(Lee, 1980; Stewart [cited in Hoopes, 1981]; Yousef, 1974)

\section{Interaction}

Motivation and incentive to communicate are not extensively considered, but, according to Dinges (1983), more attention must be paid to them in the future. Unless the situation demands interaction, there may be little to none without the communicator's interest in pursuing it. Because many work and living situations in Kuwait allowed sojourners to be observers rather than participants, this category seems particularly relevant.

While motivation is rarely considered, interaction itself is thought to be of prime importance by many researchers. In a study to determine abilities involved in functioning interculturally, Hammer, Gudykunst and Wiseman (1978) derived three main factors of intercultural effectiveness: (a) the ability to deal with psychological stress, (b) the ability to communicate effectively, and (c) the ability to establish interpersonal relationships. Brein and David (1971) found that adjustment was "highly dependent on the [sojourner's] achievement of effective interpersonal relations with hosts" (p. 216). Benson (1978) and Church (1982) found that interaction was considered to be a major factor in sojourner adjustment. Most of the literature agrees with Broome (1985) who 
concluded that positive social interaction did not guarantee successful adjustment, but that successful adjustment was unlikely without it.

Another factor related to interaction is the sojourners' perceptions of the hosts' feelings about him or her. Brislin (1981) says that adjustment is marked by perceived acceptance by hosts (p. 301). Sojourners who believe that the hosts do not like them, either personally or as Americans, will be less likely to pursue interaction while those who have positive ideas of hosts' perceptions will be more likely.

\section{Communication}

Gudykunst and Kim (1984) define communication effectiveness as "minimizing misunderstanding [which] occurs when different meanings are attached to the same message" (p. 191). Attaching similar meanings is clearly more difficult in a cross-cultural encounter but is a crucial factor of adjustment. Brein and David (1971) said that an effective exchange of information between the sojourner and host was central to adjustment.

Hammer, Gudykunst and Wiseman (1978) list four abilities related to Factor II (ability to effectively communicate) of intercultural effectiveness. These are as follows: (a) the ability to enter into meaningful dialogue with other people, (b) the ability to initiate interaction with a stranger, (c) the ability to deal with communication misunderstandings between self and others, and (d) the ability to deal effectively with different communication styles.

Martin's (1987) discussion of intercultural competence also supports the importance of communication abilities. Her fourth factor of intercultural competence is the ability to facilitate communication, specifically the ability to identify cultural differences in language and to identify the implications of these differences in interpersonal communication. 
Arab and American communication styles. Much international attention has lately been focused on the differences between Arab and American communication styles. That there are great differences is something many are now aware of; what these differences are and what effect they actually have on communication is less evident. In the belief that the sojourners would also have difficulty discussing particular differences, the researcher included specific categories for guidance in this section of the interview, as was done in the section on Attitude toward Difference. These were generated from a number of sources who agreed that the following polarities summarized the essential areas of difference in American and Arab verbal communicative styles. (Adelman and Lustig, 1981; Cohen, 1987; Hall, 1979; Lamb, 1987; Lee, 1980; Nydell, 1987; Shouby, 1951; Suleiman, 1973; Yousef, 1974). In general, it is said that while Americans tend to be direct, impersonal, and informal, Arabs are usually indirect, personal, and formal. Americans are more likely to understate while Arabs exaggerate. And, finally, Americans communicate with a low priority placed on social desirability as opposed to the Arab tendency emphasizing the importance of high social desirability.

Non-verbal differences can be noted in the following: (a) gestures, (b) personal space, and (c) the use of eyes.

\section{Stress Management}

According to Lazarus and Folkman (1984), "Most stressful situations are ambiguous to one extent or another" (p. 187). In learning how to survive in a new culture, the sojourner encounters a great deal of ambiguity, which can be stressful. As a result, coping with stress is part of several discussions on adjustment. While it is perhaps not more stressful than living in the U.S.A., the factors causing stress in the intercultural setting are different. Kealey and Ruben (1983) use the term "tolerance for ambiguity" to describe a major characteristic of the successful intercultural communicator. Living in the new culture is likely to lead to many experiences in which sojourners are confused and 
frustrated by things they can neither control nor understand. It is necessary for sojourners to learn to deal with these ambiguous situations without excessive discomfort.

Hammer, Gudykunst and Wiseman (1978) label the ability to deal with psychological stress as Factor I (out of three) in their description of intercultural effectiveness. Barna (1976) also deals with stress, first naming anxiety as a stumbling block in intercultural communication, and later, more extensively, in a discussion of culture shock reactions in terms of theories of stress (1983). Brislin (1981) listed the ability to function during everyday activities without stress as an indication of adjustment.

Another much talked about factor in adjustment is culture shock. Oberg (1960) popularized this term which he defined as the "anxiety that results from losing all our familiar signs and symbols of social intercourse" (p. 177). J. Bennett (1977) uses the term "transition shock" to describe the "state of loss and disorientation we experience during any change in our familiar environment which requires adjustment" (p. 11).

How the sojourner deals with the anxiety caused by this disorientation can have long term effects on the adjustment and success of the sojourn. Defense mechanisms mentioned by Barna (1983) include hostility toward the new country, yearning for home, dependence on others, rationalization and repression. If the resulting behavior is to insulate oneself from the culture (a possible long term solution in Kuwait), one may continue the sojourn firmly locked into ethnocentrism. Further experiences may serve only to confirm initial impressions. If one, however, uses culture shock to learn about oneself and the new culture, one can progress beyond the ethnocentric stage.

\section{$\underline{\text { Satisfaction }}$}

Benson (1978) and Church (1982) both named satisfaction as an important summary measure of the sojourner's experience. Brislin (1981) said that the sojourner's satisfaction with the experience was one of four indicators of adjustment and Kealey and Ruben (1983) defined personal/family adjustment, one of three indicators of intercultural 
effectiveness, as the ability to be happy and personally satisfied with the overseas situation.

According to Dinges, (1983), "A social behaviorist analysis of intercultural competence suggests that the individual who makes a successful adaptation is engaging in processes to create a new set of social rewards for sustaining their own behavior" ( $p$. 181). An adapted individual would seek and find enjoyable, reinforcing activities. In support of this, Kealey and Ruben (1983) included "engaging in enjoyable activities" as an indicator of personal/family adjustment, one of the three indicators of intercultural effectiveness. In relation to new reinforcers, Benson (1978) cites a Peace Corps study which found that adapted volunteers in Brazil learned to participate in activities which were distinctly Brazilian.

Professional effectiveness (Kealey and Ruben, 1983), job performance (Benson, 1978) and technical skill (Cleveland, Mangone, and Adams, 1960) are often included as vital components of overseas effectiveness or success. There is thought to be a relationship between success and satisfaction. Hammer, Gudykunst and Wiseman (1978) found that most people who felt satisfied in the other culture felt that they functioned well. They inferred that these people had been successful. Brislin (1981) said, "All people want to be judged successful, but there are differing standards from country to country for assigning this label" (p. 201). How respondents describe their own feelings of success in their roles shows how they are defining success and whether or not their view is ethnocentric or ethnorelative.

Another factor affecting satisfaction is the ability to perform the necessary duties. Stening (1979) found that a congruence between one's own and the organization's expectations was a very important factor in adjustment. Brislin (1981) said that adjustment was marked by the ability to complete assigned tasks. This applies to any role. It is assumed that the frustration of being unable to accomplish tasks would decrease overall satisfaction. 
Another possible indicator of satisfaction is in regard to the changes the individual describes as a result of the intercultural experience. Church (1982) found that personal growth was a more consistent outcome than changes in more value-laden, culture based ideologies and norms. Uehara (1986), however, reported that a majority of returning American students expressed value changes evident in daily life. For example, they had altered views about male/female relationships, individualism, clothing and achievementoriented behavior.

\section{Coping Mechanisms}

This study investigates coping mechanisms, or the behaviors or activities which the sojourners engage in to tolerate the ambiguous or stressful situations encountered in the intercultural environment. In their book on stress and coping, Lazarus and Folkman define coping as, "constantly changing cognitive and behavioral efforts to manage specific external and/or internal demands that are appraised as taxing or exceeding the resources of the person" (p. 141). The aim of coping is stress reduction, not enhanced intercultural sensitivity. The result, therefore, may serve to make the sojourner more comfortable, but may not increase the development of intercultural sensitivity.

Their definition is process oriented rather than trait oriented. "What the person actually thinks or does is examined within a specific context. Coping thoughts and actions are always directed toward particular conditions" (p. 142). This definition is particularly relevant to intercultural communication since coping strategies are viewed situationally. The way sojourners cope with problems in a familiar environment is not necessarily the same as the way they cope in an unfamiliar one. The environment is seen as "providing a set of resources, constraints and demands to be used or responded to by the person" (Lazarus \& Folkman, p. 185). The intercultural environment calls for responses to unfamiliar situations in possibly unfamiliar ways. The effectiveness of the responses may have a bearing on the sojourners' comfort, and in turn, their attitudes 
toward and feelings about the environment. Thus, coping mechanisms are an integral part of the development of intercultural sensitivity and intercultural competence.

\section{Summary}

The various treatments of adjustment discussed in the literature review are incorporated into the interview schedule which appears in the Appendix. The responses in the interview will be used to demonstrate a possible relationship between widely accepted indicators of adjustment and the model in question. The methodology used to determine this is described in the following chapter. 


\section{CHAPTER III}

\section{METHODOLOGY}

\section{GENERAL APPROACH}

This is an exploratory study that employs the descriptive method of data collection and a qualitative method of data analysis. Descriptive research has been defined as "pertaining to the characterization of something or some relationship. For example, descriptive research portrays phenomena without necessarily explaining their causal connection" (Dooley, 1984, p. 27). It also focuses on "the particular actors being observed rather than on generalizations to a larger population" (Dooley, 1984, p. 274). This study is descriptive in both senses. While the discussion in Chapter V suggests possible explanations for the results obtained, it does not attempt to confirm causal relationships. Nor does it make generalizations about the American population of Kuwait or expatriate populations in general.

\section{Interviews}

Tucker et al (1981) said that "descriptive researchers collect information about events, beliefs, attitudes, values, intentions, preferences or behaviors. They collect this information through the use of surveys, interviews or observations" (p. 121). The interview was chosen for this project because of the freedom it allowed both the interviewer and the interviewee; the freedom on the part of the interviewer to make the questioning relevant to each individual and the freedom of expression and opportunity for selfdisclosure on the part of the interviewee.

According to Taylor and Bogdan, "The hallmark of in-depth qualitative inter- 
viewing is learning about what is important in the minds of the informants: their meanings, perspectives, and definitions; how they view, categorize, and experience the world" (1984, p. 88). As Tucker et al (1981) describe the role of the naturalistic researcher, "he or she is interested in people's logics of their own constitutive actions; he or she seeks the actor's, not the researcher's interpretations or meanings" (p. 119). The in-depth interview allows the participants to describe the situation in their own words, from their own frames of reference, yielding the "actor's" interpretations and evaluations. The in-depth interview was chosen for this study because it provides crucial insights into the frames of reference of the participants.

\section{The Interview Schedule}

The initial, exploratory phase of the research was begun by a qualitative analysis of the characteristics and themes described by prominent authors in the area of intercultural adjustment. The results were synthesized into the five topic areas of (a) attitude toward difference, (b) interaction, (c) communication, (d) stress management, and (e) satisfaction. Questions in each of these areas incorporated the major themes from the literature. In addition, demographic data considered relevant to the study was collected at the outset of each interview.

Within the major themes, the questions were open-ended in order to allow the subject "to respond in a relatively unrestricted manner" (Smith, 1975; p. 172). The questions were sufficiently open-ended and also interrelated to permit cross-checks throughout the interview process. The researcher had ample opportunity to clarify any inconsistencies by using the interview schedule. The questions were designed to elicit answers from the interviewees that could be analyzed in terms of intercultural sensitivity and give information as to coping behaviors employed. The interview schedule (Appendix A) was the result. 
The interview was then given to three potential subjects in the intercultural setting. The purpose of the original interviews was to allow for revision had the interview failed to yield sufficient data or had it required changes in order for the subjects to understand. These first interviews were successful, however, and no changes to the interview schedule were made. Therefore, they are now included in the total sample of 15 .

\section{Population and Subject Selection}

The 15 interviewees were drawn from the American community living in Kuwait between 1989 and 1990. All had lived in Kuwait at least two years. They were people known to the author or people who had been referred to the author as either interesting or interested.

The resulting group is composed of seven males and eight females. Their ages range from 27 to 54, the average being 40. Ten of the subjects are teachers, two, librarians, and one each, engineer, diplomat and analyst programmer. Twelve of the subjects had previous overseas experience. The length of time in Kuwait ranged from 2 years to 11, the average being 4.5. The American community was not composed so overwhelmingly of teachers, so these results cannot be used to generalize to the population as a whole. However, this does not affect the research question, which was determining the usefulness of the model, not describing the population itself. In summary, the population was limited by country of birth and length of time in Kuwait.

\section{Procedure}

The interviews lasted for one to two hours and usually took place in the subject's home. Verbal consent to be taped and included in the study was given at this time. The interviews were conducted in a conversational manner. The participants were fully aware of the reason for the interview and were very supportive. The interviews were taped so that they could later be transcribed. The subjects did not want their comments on Kuwait 
widely known or taken out of context, however, so found the assurance of confidentiality necessary. The subjects of the interviews are, therefore, referred to by number, representing the order in which they were interviewed.

After the interviews, the tapes were transcribed by the author. These transcriptions became the raw data. This raw data was condensed into the extracts which appear in the following chapter. The extracts are composed of direct quotes taken by the researcher as representative of the range of responses relevant to the category. Remarks clearly repetitive or extraneous to the category are not included.

Analysis

The second phase of the research consists of coding the responses. Taylor and Bogdan (1984) said that one aspect of qualitative research is that researchers do their own coding and analysis. "Throughout analysis, researchers attempt to gain a deeper understanding of what they have studied and continually refine their interpretations...[They] draw on their first hand experience with settings [and] informants...to make sense of the data," (p. 130). The responses were considered twice in order to answer the separate research questions. For the first research question, the purpose of the analysis is to indicate whether or not individuals look reasonably consistent across categories. To determine this, the extracts are analyzed in terms of the predetermined framework which follows in this chapter. They are then coded according to the level reflected in the response.

Subject 1 , for example, gave a total of 15 responses. Nine of the responses were coded as representing Defense and are marked DF, two are marked $\mathbf{M}$ for Minimization, and four are coded AC for Acceptance. The coded interview extracts appear in Chapter Four.

\section{ANALYTICAL SCHEME}

This section explains the framework used for coding the responses according to level of intercultural sensitivity in order to answer the first research question. It is situa- 
tion specific and it explains how each question can elicit responses at every level of intercultural sensitivity. After transcription, the answers given are analyzed according to this framework. If the model is useful, answers to the questions should yield results which are consistent for the individual; in other words, a person's responses should generally cluster around one level, not range from Denial to Integration.

The framework is specific; coding rationales are proposed for each question or small group of related questions. They are arranged, therefore, in the order of the interview itself, with the interview question appearing directly above for purposes of clarity.

\section{Attitude toward Difference}

A. Do you see differences between Kuwaiti and American culture? Why do you think it's different? How do you feel about that?

B. Is there anything you prefer about Kuwaiti culture? American?

Denial. No differences or very superficial differences will be noted. It is unlikely that the former will occur, but it is possible that someone may only be aware that, for example, they dress differently in Kuwait.

Defense. At this level, many differences will be noted, but most will be denigrated.

Minimization. Differences recognized will be superficial; behavioral differences will be mentioned, but a sojourner at this level will attribute "universal" intentions and assumptions in explanations.

Acceptance. Differences will be recognized and will not be denigrated. An individual at this level is likely to see the differences as interesting. The explanations may reveal a naive understanding of Arab culture, but indicate enthusiasm and nonjudgementalness.

Adaptation. Explanations show good understanding of Kuwait. This individual can understand the meaning of events. This individual has the ability to empathize. Empathy "involves the imaginative participation in a different world view" (Bennett, 
1984, p. 41). This individual's explanations show an ability to see things from the Kuwaiti point of view, and an ability to shift frames of reference.

Integration. This individual is able to evaluate experiences in the context in which they occur. There will probably be statements indicative of "marginal" cultural identity; this person is neither completely "American" nor "Kuwaiti," but has incorporated aspects of both cultures into a world view.

C. When you have a holiday, what's your first choice?

An answer to this question will show either a positive or negative attitude toward difference in general. Some sojourners will seek more difference and be enthusiastic about more new experiences; others will be anxious for familiarity.

\section{Interaction}
A. How important is it to you to have good communication with Kuwaitis? Arabs?
B. How much interaction do you have? What type? Have you established satisfactory relationships with Arabs?

Denial. At this level, interaction may not be very important. Responses indicate an us/them viewpoint.

Defense. The ethnocentric individual may not feel that interaction is very important and may indicate the assumption that "they" need to learn how to communicate with "us." If interaction is important, the individual at this level may be satisfied with a relationship that reflects a superior to inferior relationship. Or, they may be unsatisfied and lay the blame on negative traits that they attribute to Kuwait.

Minimization. Communication is probably important. These individuals feel satisfied with relationships. They have probably found that they have been accepted for "who they are." They may feel that few changes were necessary and that it has been sufficient to "be themselves." 
Acceptance. Communication is important and this individual is probably satisfied with relationships. New patterns have developed, but are in response to external differences.

Adaptation. Same as above. Changes in behavior, however, are generated from within. A new frame of reference determines what is or is not reasonable.

Integration. This individual can shift frames of reference and evaluate the quality of interaction from both American and Kuwait perspectives. The sojourner at this level may describe personal growth that developed from interactions.

C. Do you think you are perceived positively or negatively here as an individual? as an American?

Denial. These sojourners may indicate little awareness of how others perceive them. They don't find anything unique in this situation and probably indicates a feeling that people see them the way they always have.

Defense. Many American sojourners with previous overseas experience, particularly in the developing world, are accustomed to deferential treatment. This was not very common in Kuwait, where nationalism and pride were openly exhibited. The ethnocentric sojourner tended to see this treatment as arrogance.

Minimization. Being American is seen as irrelevant. These sojourners believe they are appreciated for their personal qualities.

Acceptance. The ethnorelative sojourner recognizes that, despite a lot of anti-U.S. government sentiment in the Arab world, the American individual is usually seen as separate and distinct from the government. Women in particular may feel that they are not given respect in the Arab world due to vastly different behavioral norms, but the ethnorelative woman should recognize that in many cases, she is failing to conform, to dress styles for example, and thereby open to being misunderstood. Negative perceptions are explained by cultural differences. 
Adaptation. This individual demonstrates a clear understanding of the two cultural frameworks and how they affect perceptions.

Integration. This individual can interpret behavior from either perspective and is aware of the effect behavioral choices made have on others' perceptions.

\section{Communication Skills}

A. Have you had any communication problems? Why do you think that's a problem? How does it make you feel?

B. What problems have remained? Why do you think so? How does it make you feel? How do you handle it?

Denial. Some people may not be aware of any problems. If problems are recognized, they may be primarily blamed on an obvious difference like verbal language. Such sojourners often find very loud speech or omission of all English articles an effective means of dealing with the problem. The author frequently observed Americans shouting at non-native speakers or breaking sentences down into commands like, "You give me paper same-same, OK?" in vain hope that this would enable them to understand English.

Defense. Many may not have solved their problems, but may have come to terms with the difficulties by denigrating the Arabs who they feel persistently, and often intentionally, misunderstand them.

Minimization. These sojourners recognize verbal and often nonverbal differences in ways of communication, but fail to see a difference in the underlying meaning. Individuals at this level minimize the problems encountered and fail to recognize the cultural differences at their roots.

Acceptance. People at this level recognize the importance of cultural difference in communication problems. They recognize that different styles exist and, while they may still have problems, they don't blame them on the Arabs. Interactions have led to changes in specific communication behaviors. 
Adaptation. These sojourners indicate a greater understanding of specific cultural differences and their effect on communications. They have altered behaviors in response to a perceived need to communicate differently. A new frame of reference determines what behavior is appropriate.

Integration. Success or failure to resolve communication problems is discussed in terms of cultural difference.

C. Is there anything that used to be a problem but isn't now? What has changed? What made you realize the need for a change? How did you do this? How did you know it was effective?

Denial. Sojourners at this level may perceive fewer problems now, but indicate little awareness of what changed.

Defense. Problems which have been solved are those in which the sojourners believe they have been able to make the Arabs do things their way, i.e., the right way.

Minimization. Solutions involve the ability to see how similar we all really are.

Acceptance. The ethnorelative individuals take responsibility for their situations. Cultural difference is at the heart of the realization of a need for a change. The individuals at this level have tried new behaviors to solve their problems. These new behaviors are in reaction to external events.

Adaptation. The solutions attempted by individuals here indicate cultural understanding and the ability to empathize. Unlike those individuals at the acceptance level, the new behaviors are generated from the new frame of reference.

Integration. Effective and ineffective solutions are evaluated in terms of the cultural context.

\section{Stress Management}

A. Do daily activities cause stress? Why do you think that occurs? How do you feel about it? What do you do about it? 
Denial. These individuals may experience very little stress indicating an inability or refusal to recognize great differences. Or, they may experience a great deal of stress and have gained no insight as to why it occurs or how to handle it.

Defense. These individuals probably find many things stressful. Stress is exacerbated by the attribution of negative traits to explain it. It is probable that no positive action has been taken. Coping behaviors include the expression of anger or bitterness at "their" continued aggravating behaviors.

Minimization. This sojourner may deny stress and will deny that difference is the base of any examples of stressful situations.

Acceptance. This sojourner admits to some stress. Explanations for stressful situations include the possibility of differing values. These explanations may or may not be accurate, but the sojourner has found a way to cope without blaming Kuwaiti culture.

Adaptation. Same as above. This sojourner's explanations indicate a clearer understanding of differences which may lessen stress. This sojourner does and perceives things differently in Kuwait than in the United States. Fewer situations are incomprehensible as a framework has been established.

Integration. This individual may have less stress than above because the cultural switch comes more easily. Having another frame of reference allows the individual to interpret new situations with reasonable accuracy. This individual should express feelings of comfort with a variety of behaviors in most situations.

B. Did you experience culture shock? How did you handle it?

Denial. This individual did not have much culture shock and has gotten used to the driving, the unfamiliar clothes, and other obvious differences.

Defense. These sojourners may have experienced culture shock. They may have wanted to leave and been sorry they came. Or, they may finally have gotten used to things or found ways to get around the "crazy" way things are done. 
Minimization. They may have experienced culture shock, but it is seen as something temporary, something one experiences when trying something new. The discovery that deep inside we are all the same may have helped the transition.

Acceptance. Culture shock may have been experienced. Coping with it includes learning about different customs and values, and as a result, understanding "why" has led to greater comfort and less frustration. Efforts at proper behavior may not always reflect accurate understandings of the culture, but the realization that different responses are called for is present.

Adaptation. Same as above. Learning to handle culture shock means being able to empathize. At this level, understanding "why" means not merely recognizing that Kuwaitis are indirect, for example, but also learning to communicate indirectly.

Integration. Same as above. Culture shock is seen as an opportunity for personal growth. It is a chance to review one's own values and a time for self-discovery.

\section{$\underline{\text { Satisfaction }}$}

A. Do you feel successful in your role here?

B. Are you generally able to do what is expected of you?

Denial. Yes: This person feels successful but didn't have to make any changes. Explanations for success describe means of achieving success effective in American culture.

No: This individual feels thwarted by things beyond control and is likely to feel that "they" can't do things right.

Defense. Yes: These people are good at their jobs and have been able to show "them" how to do it "right." Either no changes were necessary, or the changes made indicate condescension, having to lower one's expectations, for example.

No: "They" are incompetent; the system is wrong, etc. The defensive sojourner resorts to negative stereotyping of others to explain the lack of success. 
Minimization. Yes: These individuals are satisfied with their achievements, communication and relationships. They may attribute this to a "universal" appreciation of certain abilities. Few or no changes have been necessary because just being natural is all that is required.

No: These sojourners may feel unsuccessful because they failed to find common ground in terms of expectations or responsibilities.

Acceptance. Yes: Answers indicate a clear sense of what has been accomplished with recognition of differing needs; changes of behavior have been made and are viewed as positive. The changes are in reaction to external differences noted.

No: These individuals may not be able to explain why they are not successful in terms of cultural differences, but they do not denigrate the Kuwaiti culture.

Adaptation. Yes: Same as above. Empathy or a frame of reference shift may be revealed in discussing why certain changes were made. As previously mentioned, at this level, changes are generated by a different frame of reference. The stimulus for change is internal, not merely a reaction to the external situation.

No: Empathy may be revealed in explaining the lack of success, or why certain changes were ineffective or impossible.

Integration. Success is contextualized. This individual has the ability to define success in terms of the situation, which is, in this case, the expectations of the Kuwaiti hosts.

C. Why did you come to Kuwait? Did you accomplish this? Yes - How?

No - Why not?

Denial. Yes: Reasons indicate lack of interest in Kuwait. Goals have been achieved but they are strictly personal (money, job).

No: Goals were not achieved because "they" got in the way. 
Defense. Yes: The reasons for coming may be selfish and may also indicate a perceived need to show "them" the "right" way. Some sojourners may also indicate a rejection of their own culture and say they came to Kuwait to get away.

No: The failure to accomplish personal goals is blamed on Kuwait.

Minimization. Yes: This individual may show interest in Kuwait, but comments show a belief in basic humanity, universal truths and goals.

No: They may be puzzled by their failure, not understanding why $\mathrm{Ku}$ waitis don't see our similarities.

Acceptance. Yes: This sojourner indicates an interest in and valuing of difference. In addition to personal goals, this individual sought and found an intercultural experience.

No: This individual accepts the failure to achieve personal goals without resorting to stereotyping Kuwaitis or Arabs.

Adaptation. Yes: Achievement of goals includes gaining an understanding and feeling of comfort in Kuwait.

No: Failure is accepted without negative stereotypes. The answer indicates a frame of reference shift - an attempt to explain it from a Kuwaiti point of view. Integration. As with success, this individual views goal achievement or lack thereof contextually.

D. What aspects of your life here do you really enjoy? Do you do anything here you haven't done before?

Denial. Enjoyable activities involve other Americans almost completely. New activities may be on the level of Arab dress-up night. 
Defense. Enjoyable activities are American; new activities may involve ways of escaping or circumventing Kuwaiti customs or rules.

Minimization. This individual probably enjoys a variety of activities. Differences noted are dismissed as not being the most important aspect.

Acceptance. Both American and Arab activities are enjoyed. This individual takes advantage of a unique situation in finding entertainment and positive reinforcers.

Adaptation. Same as above. This sojourner indicates the ability to shift frames of reference when participating in very different activities and defines a good time in a new way.

Integration. This individual may relate aspects that will be greatly missed upon leaving Kuwait, not just at the activity level, but on a deeper personal level, things that have become a way of life.

E. How does the Kuwaiti experience compare to your previous overseas experience?

Denial. Little difference is noted; the answer reveals few categories for comparison.

Defense. This individual gives a negative evaluation of one or both experiences.

Minimization. This individual probably had a positive experience in all places and is unwilling to compare others negatively; universal truths have been discovered or confirmed.

Acceptance. This individual shows an awareness of differences and gives nonethnocentric evaluations when making comparisons.

Adaptation. These individuals indicate culture learning in various cultural settings. They may also relate personal growth in terms of an increasing ability to empathize in a variety of intercultural settings.

Integration. Same as above. Growth and the integration of various perspectives may have made life easier in the most recent experience, Kuwait. 
F. Would you like another overseas assignment? Why?

Note: In evaluating these answers, the author recognizes that there are many reasons, personal and professional, for staying abroad or returning home and the choice in itself is neither ethnocentric nor ethnorelative.

Denial. This individual's reasons for choosing or not choosing another overseas assignment would relate to the benefits or disadvantages of the expatriate lifestyle.

Defense. The reasons for wanting another overseas assignment may incorporate negative feelings about Kuwait. This individual could want the next assignment to be an improvement on Kuwait, "more open" or "non-Islamic" for example.

Minimization. These individuals may feel they can live happily and get along with anyone, anywhere.

Acceptance. These individuals indicate an interest in experiencing other cultures when opting for another assignment. Both those ready for more and those ready to return express an appreciation of the culture and the experiences.

Adaptation. Same as above. Answers at this level express an appreciation for insights gained. These insights are at the level of understanding events.

Integration. Same as above. Insights at this level are insights into other perspectives.

G. Has this experience changed you?

Denial. Any changes noted have little if anything to do with the overseas experience.

Defense. Changes noted are often negative and accompanied by negative evaluations of Kuwaiti culture. The Kuwait experience is blamed for the development of undesirable characteristics in the individual.

Minimization. This individual has either developed or confirmed beliefs in universal truths and sees the changes as positive.

Acceptance. These individuals have gained an appreciation of differences and describe personal growth which resulted from observing and learning about a new culture. 
Adaptation. Same as above. These sojourners have not just learned about the culture, they have learned from it. They see themselves and others in terms of their cultures and are nonjudgemental.

Integration. These individuals are aware of having incorporated new frameworks into a world view. They have been profoundly affected by the experience and will recognize a variety of perspectives when interpreting past and future experiences.

Summary: What advice would you give another coming to Kuwait?

Denial. Advice focuses on what to bring, etc. Any reference to difference is very naive.

Defense. This individual is likely to offer negative advice which results from the ethnocentric evaluation of differences. (How not to get taken advantage of, for example)

Minimization. This individual will most likely recommend that the future sojourner "be yourself," think positive, and look for the good things.

Acceptance. This individual indicates pleasure at differences discovered and things learned. The advice shows understanding of behavioral and some value differences, focusing on being nonjudgemental.

Adaptation. Same as above, but including advice as to how to change one's perspective as a way of coping with problems.

Integration. These individuals show good cultural understanding and the ability to empathize; they may have more difficulty than others in giving advice as they might not be conscious of empathic decisions made. The answer is also likely to include advice about being open to a learning experience and taking advantage of an opportunity for personal growth. 


\section{COPING MECHANISMS}

Throughout the interview, interviewees were asked to describe actions taken to cope with the intercultural situation. The developmental aspect of the behavior is analyzed in terms of the model; does this behavior encourage or discourage movement on the continuum? Those behaviors that encourage movement are examples of developmental adaptation; those that inhibit movement are nondevelopmental. An individual who has solved communication problems by reducing intercultural contact to a minimum, come to terms with the resulting difficulties by blaming Arabs and assigning negative traits to that group is seen as exhibiting nondevelopmental adaptation. On the other hand, one who says, "I used to get angry at the pushing, but now I know they don't really mean it. We all want the same thing," shows developmental adaptation. Although it is still ethnocentric (Minimization), it represents a move from Defense to Minimization. 


\section{CHAPTER IV}

\section{RESULTS}

This chapter presents the findings answering the two research questions. The first part of this chapter contains the coded interview extracts and the second part comprises the findings related to coping mechanisms. The extracts are presented by interview subject and grouped according to topic area. Each response is numbered and labeled with a level of sensitivity according to the criteria established in Chapter III. A summary of topic areas and questions is presented below, followed by the extracts themselves. Throughout this section, DN refers to Denial, DF to Defense, $\mathbf{M}$ to Minimization, AC to Acceptance, AD to Adaptation, and I to Integration.

The second part of the chapter addresses the second research question. In this section of the paper, the categories of coping responses which emerged are presented and identified as developmental or nondevelopmental. The rationale for determining this is explained at the same time.

\section{SUMMARY OF QUESTIONS}

\section{Attitude toward difference}

All of the questions in section 1 relate to attitudes towards difference. They include asking for examples of differences noted between Kuwaiti and American cultures, ideas about why those differences exist and how the differences make the sojourner feel. 


\section{Interaction}

The questions in section 2 are related to the importance of intercultural interaction to the sojourner. They include questions about the amount of interaction and the sojourner's feelings of satisfaction with these interactions.

\section{Communication}

This section is related to communication problems. Sojourners were asked to give examples of communication problems and solutions arrived at. They were also asked to describe specific differences in communicative style, give possible explanations for the differences and describe their feelings in relation to these differences.

\section{Stress management}

This section has two parts. Part one is related to stress caused by daily activities and part two deals with culture shock.

\section{Satisfaction}

These questions include personal feelings of success, reasons for going to Kuwait and achievement of those goals, overall satisfaction, a comparison of Kuwait to any other overseas experiences and any changes caused by the experience of living in Kuwait.

\section{$\underline{\text { Advice }}$}

The only question in this section was, "What advice would you give to another coming to Kuwait? 


\section{INTERVIEW EXTRACTS}

\section{Subject 1}

The first subject was a 35-year-old male teacher who has spent 2 years in Kuwait and had no previous overseas experience.

Attitude toward difference. 1 . Here they're tied to their family very closely and they have to be concerned about their family's appearance to other families. I consider it debilitating for anyone that has individual spirit. DF

2. Women are the caretakers of the culture here and it's really to their disadvantage. They have created a power structure themselves, too, so within their prescribed area they have a lot of control. They don't feel like they're missing anything. DF

3. Lateness isn't important. One thing I guess is they feel they can't do anything about it. I'm often late and just go, "Oh well," cause they'll accept me if I'm late. You just ease into it because there's no pressure. AC

Interaction. 4. I have some interactions, mostly at work. I haven't made any changes really. Being myself means I tolerate a lot from other people so I've just done a lot of that. $\mathbf{M}$

5. I think being an American might be negative. They see the necessity of having us here but I think they wish they didn't have to because they keep reminding us we're unqualified or incompetent. DF

Communication. 6. [Communication problems are] just feeling awkward and not knowing what to do. So then you just feel embarrassed afterwards. I don't want to go through that again. And feeling that a lot of it was just that they wanted to tell people they had foreign friends. DF

7. I know now things I shouldn't bring up. And I know what things are going to lead to. And I know what's going to make them laugh more. At first you don't realize 
what's funny. It happened slowly but I can tell it works. They enjoy my class more. AC

8. I think something in our culture supports the fact that you shouldn't waste time. You're afraid to say, "Get to the point" cause you're afraid you'll offend them. So you just play the game. A cat and mouse game. DF

Stress management. 9. Yeah. There's an amount of stress in dealing with anybody outside because something could happen and you don't know how to deal with it. DF

10. I saw people getting angry around me and I saw that it only made things worse for them than if you quietly went your way and let people butt in front of you, you'd get it done eventually. DF

Satisfaction. 11. I question what they think and that's different for them. I've been trying to change the curriculum to be more student oriented. I didn't have to change myself. $\mathbf{M}$

12. It's opened up the whole world to us. And whether it's good or bad, it's the way they do things here. I really wanted to go out of the States. AC

13. I love doing the theater. I sleep in the afternoons. We've changed our eating habits. DF

14. I think about Arabs in a different way. I think a lot of the time they've got a chip on their shoulder because they consider that Christians have taken over the world and they're defensive and have to compensate. I can understand how they feel. Being here and being a Christian you understand it. AC

Advice. 15. Consider yourself as being an observer. I think they're going to have to be tolerant. You're going to be looked down on to some degree. DF

\section{Subject 2}

The second subject was a 30-year-old female teacher who had lived in Kuwait for 2 years and had no previous overseas experience. 
Attitude toward difference. 1 . I think it's just awful here, especially being a woman here. The suppression of individual creativities. The individual is always sacrificed for the family, the society, the religion. DF

2. I haven't changed. If anything, it's made me more defensive. I'm tired of not being able to look people in the eye on the street, or sit where I want on the bus. I'm tired of men slowing down and honking. DF

Interaction. 3. [Interaction] doesn't really matter. But at work, we always get along nicely in a very businesslike way. I think everybody's tried to find a middle ground on their own. DF

4. I'd say Americans are perceived negatively out and about. I think they perceive Western women as threatening to their culture. DF

Communication. 5. No [communication] problems, but then I haven't been in a situation where there are a lot of non-English speakers. I just don't go to these parties. It's just another wasted evening - smiling and listening to stories about colicky babies which I can't relate to. DF

Stress management. 6. It's very stressful. It just builds and builds. In January, I just sit and read about anyplace else in the world. People are watching you. I can't stand it. I think it gets stressful even shopping in smaller co-ops. Because Americans are used to space. And you go into these little places and you just get really claustrophobic. Again they're mostly men and you're bumping against them and there's this great look of hope and expectation because they've bumped your elbow and it drives you nuts. It really drives you nuts. DF

7. Culture shock? Yes, definitely. After the first week, I said, well this was nice to see for a week. Now I know what this city is like. I've seen the people and I don't like them. Let's go home. DF

Satisfaction. 8. I haven't made any changes. DF 
9. We came for the job, money. This is your life while you pay the bills and get some money behind you. DF

10. Satisfactory overall. I think it's very important for people to get out of their culture and into another one. Not only to appreciate what they have, but to realize the world is a smaller place than what we as insular Americans tend to think. But I'm getting more cynical about mankind as a whole. I'm disliking it more and more. $\mathbf{M}$

Advice. 11. I'd tell them you have to make your own reality here. You need to be able to get a lot from within. If you don't have that ability, you shouldn't come here. Come with inner resources and come prepared. DF

\section{Subject 3}

The third subject was a 48-year-old male diplomat who had been in Kuwait for 4 years and had spent 20 years in Europe, Africa and Turkey.

Attitude toward difference. 1. Life is centered around the family. They're more restricted because they don't want any bad things reflected on the family. They stick together and help each other. Americans still do, but not the way they do here. I think that part's good. But it's not good because it means if you come from a big powerful family, you can get away with a lot. $\mathbf{A C}$

2. I think censorship is carried a bit far, but I can understand about nudity. I don't want to impose our culture on them. AC

3. My first choice is to see the places in the region because I'm here and why not see them. But once a year it's nice to get back to a place more like our culture - to let your hair down. AC

Interaction. 4. Communication with Kuwaitis is very important. AC

5. The main change is that you have to very adaptable and very patient. AC 
6. I'd say yes because I think that if I were some other nationalities I'd be perceived differently - say from a third world country. But I think Kuwaitis basically like Americans. AC

Communication. 7. It's been easy to communicate with all the different Arab groups. They're very friendly and terribly hospitable. The main difference - at least with Kuwaitis - the interaction is more in keeping with their traditional values. Rarely do I see, let alone meet, any Kuwaiti females. AC

8. In both business and social things where you think you can accomplish something and get to know something quickly, you find it takes longer. It takes awhile to understand you're not going to get there directly. You gradually get these vibes or hints of what their feelings are. $\mathbf{A C}$

9. Sometimes I think I've been here long enough where I think like they think. Maybe at first it seemed like a problem but you don't think about it anymore. It's the way of life. AD

10. They weren't being straightforward - not that they were being deceitful, but they weren't being straightforward. AC

11. When you're dealing with people in the culture you're in, you have to do it their way. AC

Stress management. 12. Just driving [is stressful]. It's the worst thing here. Also I feel uncomfortable in a social situation being single. I find it awkward being around Arab women. I don't know how to act unless I've really gotten to know the family. AC

13. No culture shock. It's more modern and open than I expected. I've had a lot of experience with this. $\mathbf{A C}$

Satisfaction. 14. I think I've been successful. We have to look on our living here in Kuwait as representing our country in a positive way. Showing the positive side of America. I haven't made many changes - I've been to so many other places before. AC 
15. Yes, [it's been satisfactory overall]. Some of the things I've learned about this culture, neighboring cultures, have been very educational. The main thing I've learned is that the Arab world is completely different from what the media portray. The media made it sound like Palestinian and terrorist are the same thing. It blows the Lawrence of Arabia stereotype. And not everybody here is an Arab billionaire. AC

16. I think living overseas makes you more tolerant of different cultures, religions, customs. Makes you understand them much better and understand the differences. People are people all over the world. We all want to get along with another, we want a home to live in, clothes to wear, food to eat. And we all want something better for our children. A man's a man wherever he is. A woman's a woman. I'm not saying women here want the freedoms American women have. I don't think that's the case or should be. But we want medical care, a decent place to live. Decent is different wherever you are. But to live in peace and be able to tolerate the differences we have. AC

Advice. 17. Come with an open mind and judge for yourself. Also being patient. But first you have an open mind and then decide if patience is required. Any negative things you hear, don't let that make up your mind that that's going to be negative for you too. $\mathbf{A C}$

\section{$\underline{\text { Subject } 4}$}

The fourth subject, a 32-year-old female teacher, had spent 3 1/2 years in Kuwait and had lived in Columbia for 7 months and Puerto Rico for $11 / 2$ years.

Attitude toward difference. 1. I think we're on two different wavelengths. We have friends from other cultures but I could never meet their families. When I'm with Kuwaitis they do Western type things and then go off and do something else. DF

2. I'm not sure I want to bridge the gap because I think I'd do more harm than good. I can't get close to a Kuwaiti woman because they see me doing things perhaps they'd like to do. DF 
3. The family unit is different. I think it's good to have a strong family but perhaps they've taken it too far. I couldn't take that much interference in my life. DF

4. And despite this [importance of family], they're raised by servants. They seem to have no perception of space around them. The world revolves around them and I think that's because they're used to being waited on. DF

5. I like the slow way of life - tomorrow, tomorrow - but it drives me crazy when I have to get something done. DF

Interaction. 6. Very little interaction. It's satisfactory - at work I can operate in the American way, but there's very little communication. DF

7. I have some good friends. But no changes. And that's why they're good friendships. DF

8. I don't think being an American makes any difference. The only thing that has any bearing on how I'm perceived would be my Western appearance. Some people can accept it and some people think it's bad. DF

Communication. 9. I don't think [I have any communication problems]. I can always get my point across. If there's a problem, I'd say it's because we're trying to push ourselves on each other. DF

10. At least I recognized when we were talking in circles so I stopped. They won't say "No," so I keep thinking they're agreeing with me but after ten phone calls, forget it. I don't know if it was conscious, and they never intended to agree, or just an inefficient system. DF

Stress management. 11. Driving is highly stressful and I can't get used to shops being closed in the afternoons. DF

12. I definitely had culture shock and it took me a long time to get over it. We had no support mechanisms. I felt horrible. I wouldn't unpack. At first I thought Arabs were people who hassled you on the streets and I thought they were a kind of people who 
really love children. I no longer see them as people who hassle you on the streets and I don't see them as people who love children. DF

Satisfaction. 13. Yes, [I feel successful]. I've become well-known in the schools here. I've gone from being unemployed to being part of an administrative staff. DF

14. We wanted one more overseas experience but it's been a letdown - we came to have an intercultural experience but we're being kept too separate. And we were broke. DF

15. Definitely satisfactory - the friendships with other Americans primarily. DF

16. I enjoy the beach, making wine, drinking flash (homemade liquor). There's not a lot to do. DF

17. I'm sure they don't want Westerners to come in and take over. And with reason. It's their country and should be done their way. AC

18. The biggest difference is socialization - making friends with the people. In Colombia I learned all my Spanish in the bars. People are kept separate here. I'm not saying it's good or bad, just that it keeps people apart. AC

19. I'd go to a non-Muslim country with alcohol. DF

20. It's aged me - stress and overwork. Maybe it's those unwritten codes. Maybe it's because I don't know the language so I always feel like an outsider. The language coupled with the big cultural gap. I've bridged neither one. DF

21. I think I've become more patient. Instead of jumping to conclusions, I've learned to wait. I learned that through jumping to wrong conclusions. AC

Advice. 22. I'd tell her not to bring sleeveless things, short skirts. I'd show her how to make wine. I think it's hard for an American to recognize she's irrelevant 'cause we're used to being looked up to. DF

\section{Subject 5}

The fifth subject was a 35-year-old female teacher who had lived in Kuwait for 11 years and had no previous overseas experience. 
Attitude toward difference. 1. Islam's gotten much stricter. I don't enjoy the changes but they don't infringe on me too much. I'm used to them now. I used to go out in skimpier things but after you get looked at a few times, you don't do it. You know how to make yourself feel comfortable so you just do it. AC

2. It's their culture. I do what I want. Nothing holds me back 'cause I'm female. You're safer too. And it's a slower pace - more family time. We go to Cyprus a lot beach holidays. Or back to the States. DF

Interaction. 3. It's difficult to have good communication with Kuwaitis. Their culture's different. Their ideas about family, child-raising, about marriage are all different. It's such a strain when I'm with them. They're really ready to give advice. They want to know when you're going to have another baby. DF

4. Good relationships - yeah. The changes would be to be tolerant and accepting that this is the way it's going to be. If you don't, it just makes it harder for you. It's not going to change in your favor. DF

5. If they like you, they accept you. If they don't, they don't. Being an American I don't think has much to do with it. They like you to be easygoing and friendly. I think that's all that matters if you don't do anything against what they believe. M

Communication. 6. Their work ethic is much different. They don't work as hard as Westerners do and you have to learn not to expect it. DF

7. They don't have discipline. Their children are all running around, screaming and the teacher can be talking at the same time. It's frustrating. And everybody's business is their business. That's the way they are. You just cope. You just ignore it. DF

Stress management. 8. Driving and shopping [are stressful]. They don't know how to be orderly. They don't know how to line up. And people with the most money and biggest cars think they should go first. DF 
9. I don't know if I had culture shock. Once I got used to everything I just did it and it was a big adventure. $\mathbf{A C}$

Satisfaction. 10. Yeah, [I feel successful]. I wouldn't have been a teacher if I wasn't here. I like working. I like being a mother. I've been able to do everything without a lot of stress. DF

11. Definitely satisfactory. Not worrying about money, childcare, travel. [We do] nothing new. Just American type things that we'd never do in the States - bowling, cross-stitch, softball. DF

Advice. 12. Have an open mind. Don't have any preconceived notions about Kuwait. What you do depends on who you're with. AC

Subject 6

The sixth subject was a 35-year-old male engineer who had spent 11 years in Kuwait and had lived in Panama for 5 years and in Germany for 2 years.

Attitude toward difference. 1 . Well, when they say one family, they mean something different. They mean mother, father, aunts and uncles. It's different out of necessity. In the old days, they were tribal, in a harsh climate. They had to have a close-knit organization. It hasn't been that long since that was totally true. AC

2. They've always separated the womenfolk from the menfolk. It's come up through the culture. It's fine for them. I guess I believe in freedom but as long as I don't feel encumbered by the social roles, I feel fine here. AC

3. And doing business here - it's on a handshake, on a smile, on a greeting. If you go down to the man's shop, you see him, you have a cup of tea and you can do business very easily. I like that. AC

4. You've got to have patience, but when the man says he's going to do it, he'll do it. He didn't say when or how or to what extent. He does it in the way he sees he's following through. AC 
Interaction. 5. I think between a Kuwaiti and Jordanian you can only go so far. But for a Western, non-Arabic speaking Christian, I think the line is very hard to pass. You're a welcome guest at all times but never totally accepted. AC

6. At work, I've got to maintain rapport. I don't get my recommendations delivered unless I'm mobile, seeing everybody. AC

Communication. 7. If you just sit there, nobody comes in or calls you on the phone. It was easy to discover they weren't going to ask me. You think, "They don't like me." Or, "They know it all and don't really need me." I'd lose my job. You get motivated at that point. You've got to find out how you can be beneficial. I'm the mobile one. If they're not going to come to me, I'll go to them. AC

8. I don't need to know why. In the beginning, they would not know what questions to ask so I'd have to ask them for them. AC

9. I don't understand how the decision process works. They just don't make decisions. If you make a decision, you have to live with it. If you don't make any deci sions, you can't be wrong. I guess if something's gotten to me that would be it. DF

Stress management. 10. Driving [is stressful]. You just have to get used to it. I don't remember any culture shock. It's very easy here. $\mathbf{M}$

Satisfaction. 11. Definitely successful - I might stay ten more years. The financial aspects are great. DF

12. I've learned patience. And in working with people, personalism is really important. Be ready to spend some time and you'll get things done. AC

Advice. 13 . Be ready to accept the changes. Be ready to wait for a few things. Enjoy what you can. Liking where you are has a lot to do with the people. Though that's a problem. Friends come and go. AC 


\section{Subject 7}

The seventh subject was a 35-year-old male teacher who had been in Kuwait for 9 years. His previous overseas experience consisted of travelling in Europe.

Attitude toward difference. 1. There are lots of differences, but I think the biggest surprise is that there are so many similarities. If everyone here took off their dishdashas \{white robe worn by Kuwaiti males\} and put on Stetsons, you could almost believe you were in Texas. All the big cars, a lot of bravado, very materialistic. Probably because there are so many newly rich people in both places. I don't think about it much because it's so much like most Americans. $\mathbf{M}$

2. But the religion of course is different. I'm a bachelor and not a Muslim so I'm not allowed into family situations. It's Islamic tradition that it's not good to tempt single men around women. They believe that people are basically evil and our first instincts would be to jump into bed together so society should do everything it can to keep us apart. AC

3. Sometimes it's frustrating that Kuwaitis are so nonchalant about things but I've been here long enough that I really appreciate that. They're not self-conscious about what you're doing and what they're doing. If they decide they like you, they like you for whatever you are. They accept incredible differences in people. If some place in America were overwhelmed by hundreds of people in dishdashas, they'd probably start burning their houses. But I do miss the way it's easy to get things done. AD

4. I like Turkey. It's cheap and beautiful and large. And it's nice to go places where you don't know what's going to happen next, where you're going to be surprised. AC Interaction. 5. Yeah, [interaction is important]. Almost all of my students are Kuwaiti and I try to understand how they feel about me and my culture and how I feel about theirs. AC 
6. I used to spend all my time outside work with Arabs, not Kuwaitis, but Lebanese, Palestinians. But where I live now there aren't as many people interested in the West. I might have changed but it was so gradual I didn't notice. And too, when you're in a foreign country, the people that you meet are often people interested in your culture so they're not typical representatives. AC

Communication. 7. I know when I first came, it was irritating. The attitude towards time, when you make an appointment and in fact it just means if nothing else comes up. Maybe it's just a polite way of taking your leave. And they're not obsessed with making every minute count. They have a more relaxed attitude. Now, I do the same. At first, I felt they were irresponsible, so unreliable. But it's not a personal thing. AC

8. When I came here, I was very deliberate about everything and quite introspective. I think Arabs are much more warm-blooded, louder and effusive, so actually I've become more like them. I've loosened up a bit. AC

9. I realize now that if I want to get something done, I have to talk about their brother, etc. There's no point in getting upset and so I can cope now with spending 45 minutes socializing to get 3 minutes work done. You just have to relax. AC

Stress management. 10 . No, I totally ignore the stressful things. Anytime I have to get something done, I take a magazine with me. I'm prepared to come back next week. When I first came, I'd get upset and think they were being malicious and then I realized that they don't care, so I don't either. But then, I don't have a driver's license either. That's too much hassle. AC

11. I'm not sure about culture shock. I'd been in the UK for two months and it was such a shock to find out that really the Brits are completely different. But the biggest culture shock I've experienced was going back home. I'm more relaxed and less neurotic. Lots of things about America bother me. Everybody always wants you to know everything about them. AC 
Satisfaction. 12. Yeah, I suppose [I feel successful]. At least I've always good rapport. I'm not condescending and they realize after they've talked to me that I'm actually interested in them and their culture. I'm not here just to make a quick buck. I think many people aren't successful in Kuwait because they don't like Arabs, and they can pick up on that straight away. AC

13. I came from a small town where I had to make my own entertainment and go out of my way to get on with people. And I was incredibly patient. I have such a high threshold for boredom. AC

14. I'm not as intellectually curious as I used to be. I'm lazier. It's such a mix of people nobody really expects anything of you. But it's comfortable. I have enough money to help people out. I have freedom. I just really enjoy being in foreign cultures. There's not much to see, but part of it is being able to live outside the rules. AC

15. I didn't have any personal goals when I came here; I just needed some fresh scenery. AC

16. I've really enjoyed going to little cafes and meeting people. It's really interesting - people have incredibly good outlooks and then you start talking to them, and you find out every minute of their lives has been a crisis. I think this strength comes from Islam. Their attitude is this life isn't everything and they're being judged by God. Especially the rural people - Afghans, Iranis, Baluchis. AC

Advice. 17. Learn a bit of Arabic. Have a lot of patience. Learn to keep your mouth shut and listen to what other people have to say first. AC

\section{$\underline{\text { Subject } 8}$}

The eighth subject was a 27-year-old female librarian who had been in Kuwait for 2 years. She had lived in France for a year.

Attitude toward difference. 1 . Work is very difficult - the environment is very divided. There are religious issues, ethnic issues. There's a lot of competition and a lot of 
jealousy. There's no concept of professional standards. Kuwaitis earn their positions by sitting there. DF

2. People are loyal to themselves and then they try to find a group to help them. Kuwaitis are after big desks. They tend to be more concerned about the titles. That's important everywhere but where I was trained, people wouldn't support this search for position with no skills behind it. This total lack of professional development would never be tolerated anywhere I've been. DF

3. What can you say about a country when they don't like it either. This is a generous country and they don't want to give it to anyone else. At a basic level, it's protection. Beyond that, it's gross arrogance. I was brought up to believe you work for what you get. And here, the money just pumps out of the ground. DF

4. It's this group and individual stuff. I could live with it, but it bothers me. In the US, there's a stress on the individual - you know, you make yourself what you are. I can live with it because I'm not subjected to it. But I just don't like it — no personal freedom. DF

5. People are so tied up in their families - a lot of obligations. You've made a date with people and they don't show up because they had to go visit their families. DF

6. I miss being able to do what I want. As a woman, I don't go alone. It's uncomfortable. I could deal with Chicago, but not with this. DF

Interaction. 7. [Interaction] is important. I have a lot of contact with them. But I'm a guest in their country and always will be. I'd love a more integrated life. I would've loved to have been integrated with Kuwaitis but I wasn't welcome. DF

Communication. 8. It's not just the words. They just don't know what you're talking about. It's a different understanding of time and a different idea of what's important. This one time I'd been very clear about what I wanted. I want a reasonable desk I said. [His arrangement] was awful. I was furious. He said it was perfect. I said I hated it. It went on for 
half an hour - him insisting that he knew what I wanted better than I did. DF

9. I've always been extremely direct. I always have a healthy skepticism about anything most people tell me. I don't get bent out of shape the first time, the second time, not the third, but the fourth time - watch out! DF

Stress management. 10. Everything is stressful. In social life, it's the constant search for something that won't get you into trouble. I feel very vulnerable. This pride element in these Kuwaitis; they're just as likely to give you one better. DF

11. You cope really well with things at the beginning. Because it's new, it's interesting, it's fun, it's different. Then you just want to get from point $A$ to point B and there's too many people trying to run you off the road. It's not interesting anymore. DF

12. I wasn't prepared for the divisions you find here. If you do try to cross over, you'll find you're living three different lives. DF

Satisfaction. 13. [I feel successful] in some ways. I've gotten a lot of experience I wouldn't have gotten anywhere else. But it's frustrating. I don't deal well with the heat. I'm sick all the time. I'm not getting as much out of work as I'd wanted. I'm not making enough money to stay in a place I don't like. DF

14. I don't regret having come. I came for the job experience. DF

15. I like to go to the beach. It's fun to go shopping. In the end, it becomes old very quickly. And it's expensive to have people to dinner and difficult to visit here because everyone's hours are funny. DF

16. France was very different. I was living with people who accepted me into their homes and it's very rare to find it here. DF

17. Now, I'd just like to live at home. DF

18. I'm a lot more cynical. I'm not at home here so I don't think that'll stay with me. I'm frustrated here. You have people over and all they do is complain. They could leave if they wanted. I'm hoping when I leave to regain some of the optimism I used to have. DF 
Advice. 19. I'd tell them to go to Dubai. I don't like being in a country where people are not happy and that's what this place is. Even the Kuwaitis. I'd warn people that you are out of the mainstream and if you can live with that, fine. I'd have to see a person and see what their goals are. DF

\section{Subject 9}

The ninth subject was a 45-year-old female teacher with 5 years in Kuwait. Her previous overseas experienceconsisted of 1 year in Bolivia and 2 years in Japan.

Attitude toward difference. 1. Tremendous [differences]. It's incredible to me that there is not a lot of tolerance for other people's behavior in this culture. When I first came here, I realized right away that there was a lot of ethnocentrism - people clinging to their groups. Kuwaitis are very insular. And I think it's defensive. And so is the arrogance. It's not arrogance that stems from confidence. DF

2. I miss the openness, the tolerance, the flexibility of personal freedom. But as a foreigner, I have more flexibility to live outside the rules. DF

3. One of the worst problems is that they assume an American woman is ready to lie down on the floor. I would never go to an Arab or Muslim country by myself. DF

4. I don't agree at all that women are on pedestals. I don't agree at all that we get privileges. They say that women have to be taken care of but I think that's negligible. I don't think they get deference. DF

Interaction. 5. No, [communication is not important]. In general, they're not willing to share very much about their culture. My interaction has always been mostly work. I've had a couple of Kuwaiti bosses who have been very threatened. I've had a lot more experience. The only way to get along was to be very perfunctory and superficial. DF

6. We have prestige being Americans, like most places. Still, they have a negative idea about women being loose and about the government being responsible for all the negatives in the world, and they often put it on me. DF 
Communication. 7. [I haven't had] many problems. I started studying Arabic right away. DF

8. We're very different. Americans are much more forthright and direct. They think we're abrupt. You're supposed to have greetings and talk about things. I still forget. And sometimes I just can't be bothered. DF

9. I've learned to be more reserved. I've learned to be a lot more discreet. I don't talk about personal things. I don't try to take responsibilities. DF

Stress management. 10. Not much stress. I still don't like men following me. I think there is a pressure on western women of this sort. But suddenly I stopped caring about it. I do a lot more what I want. DF

Satisfaction. 11. I don't feel successful as a teacher. English teachers are treated as second class teachers. Pay is one thing - I'd like a salary that shows they respect me. DF

12. I came because I don't have a lot of tolerance for the States. The rules are too close for me. DF

13. Overall it's been satisfactory having so many friends from different cultures. Five years at the university is good for my resume. AC

14. In Japan and Bolivia, I felt more at home but in all three places, the natives don't mix with foreigners. In Japan, I made a lot of friends but all of them were people not entirely comfortable with their own culture. The same people I've been friends with here. Bolivia was easier. I spoke the language and at least I like the culture. DF

Advice. 15. I think to join in activities - do theater, do exercise, get involved in groups. Only people who don't join in say there's nothing to do. But I don't think it's easy being a single female. DF 
Subject 10

The tenth subject was a 53-year-old female analyst programmer who had lived in Kuwait for 2 years. She had previously made business trips to Malaysia, Kuwait and Singapore.

Attitude toward difference. 1. It's hard to say. I feel so comfortable here, I don't think about the differences much. Part of it is the way they dress. Another one is the attitude towards women although that's not too bad. It can be overcome in most cases. In fact, it's an advantage. The only reason I'm in this apartment is that I'm a woman. They don't rent to bachelors. But I said, "I'm not a bachelor. I'm a 53-year-old grandmother." It means I'm respectable. $\mathbf{M}$

2. I look at it this way. I'm living in their country and if I can't accept their ideas then I don't belong here. Either accept them or live with them. AC

3. Arabs have a tendency to be very friendly, very hospitable. The Kuwaitis are a little bit more standoffish but there's still a lot very willing to help you out if you have a problem. There's a certain pride Kuwaitis have that doesn't show in a lot of others. AC

4. I want to travel some place exotic. Somewhere it's totally different from home, or here. $\mathbf{A C}$

Interaction. 5. Communication is very important. I have quite a bit of interaction - people I work with, my friends. I don't think I've changed. I've just been myself. I think it helps to be an American. M

Communication. 6. What's normal at home is too friendly here. Outside work that is. At work, they're used to working with Westerners and they realize the Western attitude is slightly different. When I'm walking in a crowd at home, my eyes are on the people's faces and here most of the time I'm looking at the ground. If you make eye contact with an Arab man, frequently they think you're interested. It makes me nervous. I don't like to be rude, but sometimes that's the only way. AC 
7. In greetings, they're different — so automatic. But they don't do that with me. The Kuwaitis in my department sound totally different than what other people say. They like their work, they work hard, they work long hours, they're productive. M

Stress management. 8. Not real stress, just a little frustration. Like anywhere. I didn't have culture shock. None at all. $\mathbf{M}$

Advice. 9. Definitely [successful]. I feel respected and accepted for my knowledge. I think because I like my work and I enjoy working with them. $\mathbf{M}$

10. I came because I wanted to live in the Arab world and I wanted to travel. Everything you'd want to get involved in is available here. I've had a lot of free time and the opportunity to pursue handicrafts, photography. And the social structure is more integrated. I've got friends here whose husbands are diplomats. $\mathbf{M}$

Advice. 11. Come. Just get involved. You can find something here if you try. $\mathbf{M}$

\section{Subject 11}

The eleventh subject was a 37-year-old female librarian who lived in Kuwait for 2 years. She had previously made business trips to China and England.

Attitude toward difference. 1 . The overall impression is that this is a culture that religion permeates. Religion and state are the-same. And the religion is one of the lack of free will. Thus a lack of responsibility seems to show up everywhere. It shows up in everything. It's the only way to explain the way they drive. It shows up at work, in their attitude towards sex - the notion that a man and a woman can't be alone together without it leading to sex. And I think it all goes back to Islam. There's not an individual control, an individual responsibility. DF

2. In some ways I admire cultures or people that have very strong values and live by those values. But I always question people who blindly accept values without having decided. DF 
3. As a woman, I should probably adhere more to the cultural mores, but on the other hand, I don't care that much. And I'm an American woman so I get excused a lot. DF

4. One thing I'm not good at keeping in mind is what you do and do not do for yourself. I moved my drawers myself and this guy was shocked. I can make a choice, to be culturally appropriate and wait for someone else or do it myself. And let them think what they want. I think they think I'm crazier than a loon. DF

5. Being an American, the worst part is that [religion] is very much imposed and it's very false. There's so much self-righteousness and hypocrisy. DF

6. In some ways I like the aggressiveness. We were driving along and this guy realized he'd taken the wrong exit on the motorway. So, he pulled out into the desert and backed up. My first reaction: “What a jerk!” My second reaction is, he had a problem, he solved it. He didn't have the same constraints on what's possible. And I have a certain amount of admiration for people who genuinely believe and adhere to a set of values; people who live by that, whether or not I happen to agree with those rules. AC

7. I can't think of a thing I miss at home. I look forward to long weekends and being able to stay here. I spent seven years traveling and it's left me with a real serious reaction to getting a plane. DF

Interaction. 8 . I knew before I came here that it was culturally closed. It's what I've read and I've found it to be true. It's endemic here. I don't get invited to dinner. Although they're very hospitable, there's a limit. One of the reasons you live abroad is to get a different experience and you need interaction with people from a different culture to get that. I miss that. DF

9. I don't have much interaction at all - just at work. I've experienced more with my European friends. Americans aren't very well liked. We're rude, gauche, offensive. The other night someone said, "I think he's not really an American." And I knew from him that was a compliment. AC 
10. Before I came, I had this notion that underneath people really are the same and since I've been here, that's absolutely not true. I'm finding a commonality way beyond what I imagined with my European friends, but with the mid-Easterners - No, never the twain shall meet. You need food, water, sleep, but there it ends. I just try to keep an open mind. I don't mind if you do if you don't mind if I don't. It's just different. AC

Communication. 11. Well, at work, it's very difficult to get a direct answer. And the whole principle seems to be not to offend anybody, to tell you what you want to hear. It's exactly like Mexico - never ask anybody for directions. If they don't know, they won't tell you. AC

12. I've discovered things that are offensive to me. The penchant for directness has really taken me aback a couple of times. The women at work think nothing of telling you exactly what they think of your hair, your weight, your clothing. Rita explained that's just the way it is here. It's not intended to be rude. AC

Stress management. 13. I come home frustrated and angry sometimes. I'm not as liberal and tolerant as I thought. AC

14. I wanted an American woman's perspective. What I did find out turned out to be true, but it's certainly not as exotic as other places I've been to. I had more culture shock when I moved to Long Island. I read The Arab Mind before I came here and it helped a lot to put everything into perspective. $\mathbf{M}$

Satisfaction. 15. I'm very happy here but it's got nothing to do with Kuwait. I like my home, my friends, the pace of life. Kuwait is there if I want to experience it, but not get involved. DF

16. I've been to China two times. Both [trips] were very short and I have a great deal more respect, a lot of genuine affection for the people that I've never felt here. Part of it is, people there wanted to build their country - but that's completely different. People there are really third world. Kuwait is third world only in terms of attitudes and 
services. But that sense of wanting to do well, again Western values, motivation and work ethic, exist in China. It does not exist here. And those are values I understand and have a lot of respect for. DF

Advice. 17. For some, I'd say don't come. I have a friend who's an extremely successful workaholic. And I'd say no, because of her pace. I'd say that professionally, there are opportunities. They may not always be recognized as opportunities at first. But if your bent is professional, in an environment like this, you'll find yourself slipping if you don't pay attention. You'll have to learn new ways of doing things. Personally, the Western community is large enough that you're going to find someone you enjoy. AC

\section{Subject 12}

The twelfth subject was a 54-year-old male professor who had spent 5 years in Kuwait, having already lived 2 years in Saudi Arabia and 3 years in Libya.

Attitude toward difference. 1. It's obvious the language and food is different and it's not significant. They seem to operate on two planes, an official plane and a private and personal plane. The standard is the personal relationship. AC

2. The differences I see between cultures are more official than basic - the personal image and the public image. I often wonder how they manage to cope with this - playing on two pianos at the same time. It's not a duet. $\mathbf{M}$

3. They lay a great stress on face here, but people are people and people and people are going to do what people do - good guys and bad guys. $\mathbf{M}$

4. They don't have the Teutonic sense of time. It's very frustrating. It's the exceptional person who is aware it means something different to us. They've become urbanized recently. Doing things by the clock has never been important. AC

5. They seem to be more approachable than Westerners. It's easy to break the ice with them. But I miss the efficiency, availability of everything. AC 
Interaction. 6. It's important but I think they don't want the communication. They have their own ways of doing things. Most just want a relationship, "Hello, how are you?" An exchange of smiles. DF

7. I try to avoid Americans. Why come here if I want to see them? It's easier to socialize with Arabs. They don't consider themselves better than anyone else except for the richer ones. DF

8. As an American, I'd say negatively. In spite of the fact that I put in more time and more effort than anyone in the whole department. There is no appreciation. DF

Communication. 9. I think they should tell us how to deal with a situation where we need information and don't get it. The fact that they're going to make you go through a lot of things that aren't necessary. DF

10. With non-English speakers, I tend to speak broken English. And the subjects are different, just because of the vocabulary. It tends to be superficial but it establishes good relations, acceptability. If I visit Arabs at home, with their wives and children, I have to talk about certain things. DF

11. I learned [communication rules]. I guess you'd call it instinct. I don't know if I've gotten better at reading situations or more blase. Just more experienced. Here they go through all this ritual whereas I would just say, "Hello." It depends on the person and the issues. You just feel the situation and do what you have to do. AC

Stress management. 12 . With the bureaucracy, there's a lot of stress. I don't know if you'd say stress or frustration. If it were really necessary - atomic bomb secrets or something - but English department? I just try to avoid the situation and pray it never happens. DF

13. Not culture shock per se, but if I lived my life in the Middle East backwards, this would be my first and last experience. But it's the fault of the university. They 
recruit foreigners and don't tell them what they do, what to expect. We might like to know about bargaining, about red tape, about do's and don't's. DF

Satisfaction. 14. The more you go by the book, the more you're not going to be successful. You just have to feel out the personality of the students and adapt your teaching. Accept them for what they are and do the best with what you have. I try to teach them at their level, try to appreciate the fact that they're different. AC

15. I like the Middle East although I'd be more interested in other countries. But maybe I couldn't make it financially. I'm accomplishing something here. AC

16. I don't like this word satisfied. I've managed. I've been able to last this long without going bananas. DF

17. I personally feel that the more difficult the circumstances, the better I cope. Most Americans are the opposite, they want comforts. In Libya, there was none of this. Everything was difficult, but I was happy. DF

18. The deciding factor is the attitude of the university, the way you're treated. The fact I've stayed here five years doesn't mean that I feel Kuwait is better than Libya. DF

19. I'd like to go to Mongolia. Far away from everybody. I either want the extreme of nothing or the States. It's frustrating. You think you can do something and you try but you can't do it. DF

20. Libya has changed me positively but this has been the opposite. Life here is an exercise in unnecessary frustration. There are people here who don't want you to do anything. DF

Advice. 21. To the English Department? Don't come. To Kuwait? Don't think twice, think a hundred times. Unless they're willing to orient the person. Find out - are you the kind of person who can put up with this? DF 


\section{Subject 13}

The thirteenth subject was a 40-year-old female teacher who had lived in Kuwait for 3 years, 2 years in Saudi Arabia and 6 months in Bolivia.

Attitude toward difference. 1 . The biggest difference is that they're not worldly people and that's due to their religious upbringing. Islam is a very stifling religion. I don't like the mixture of arrogance and ignorance which is predominant. You can't have an in depth intellectual discussion. It's almost childish. DF

2. When I came to Kuwait I had an open mind but I think you develop racist attitudes. You try to get past it and be a more spiritual person and say, "OK, we're all the family of man." And you meet some rude son of a bitch and say, "You — Indian!" The women of the scarves have created a stereotype I didn't even know about before. When I see a woman in hejjab \{Islamic headcover\}, I'm leery of her because they tend to be rotten drivers, very pushy and like nobody can touch them because they're wearing that. DF

3. I like the lack of restriction. If you want to go camping, you don't need a permit. And if I get stranded on the highway, I know someone's going to help me and I don't have to worry about them murdering me. In the States, are we so free that we've lost our freedom? It's much friendlier here in a way. At the Sheraton, they shake your hand. It's so personal here, and it's nice. $\mathbf{A C}$

4. I miss the intellectual stimulation in the States. The freedom to pursue any kind of knowledge. I resent the blacklists, the power, the authority figure. DF

5. They say an Arab family is so united but I wouldn't put it past somebody to pull the rug out from under their father if it meant money. We don't know about them. We don't go to their houses. They come to ours. I think it's their tribal sense of family. They don't trust me so why should I trust them? DF 
6. And they have a very different idea about children and often I don't think it's good. They either spoil them rotten or over-discipline them. They don't care if the kid has knowledge. They just want the grade. DF

Interaction. 7. [Communication with Kuwaitis] is not very important. But we have a lot of friends and I know a lot of women who are married to Kuwaitis. I like to go to parties where there's a good mix. DF

8. With some people I have to talk in a simplistic way but maybe that's because of the language barrier. I can be myself with the parents of my students. $\mathbf{M}$

9. I think Americans are perceived very positively. It changes when they get to know us and it's good. They like us much better than the Brits. $\mathbf{M}$

Communication. 10. Yeah, I've had problems with parents. The worst was a personal problem. I haven't really solved these problems. I'm just very careful of what I say here. There's definitely a difference but I'm not sure I could pinpoint it. DF

Stress management. 11. Driving [is stressful]. They've come so quickly into the twentieth century. They're out of control and they don't know how dangerous it is. AC

Satisfaction. 12. I feel successful as a teacher. The situation here is very stressful now, though. I'm definitely satisfied. I feel really safe here. It feels peaceful. DF

13. Kuwait's more interesting than Saudi and much less frustrating now. I'd like another overseas job. I'd like to go to a non-Arab culture next time. AC

15. It's a quiet, relaxing life here. It gives you more time to be introspective. In that sense, it's been really good for us together. DF

Advice. 16. I'd definitely say do it. It's good experience. It broadens your viewpoint and gives you a different perspective of America. I don't think they should stay in a closed environment. You definitely grow from that. AC 
Subject 14

The fourteenth subject, a 35-year-old male teacher, had spent 3 years in Kuwait and 2 years in Saudi Arabia.

Attitude toward difference. 1. The way Kuwaiti culture operates is that nobody takes responsibility. You don't know who to confront about a problem. And the work ethic. Here you do your job only when you have to. DF

2. It maintains the status quo. It's not baksheesh (money\} like in Saudi. Here it's wasta \{influence\}. It's really frustrating when you want to get something done. And it's not the language that matters here - it's my connections. DF

3. It's safer here. And slower, although it's more tiring. I think the safety is part of Islam. And there's less poverty. But I miss the information, the media, and the arts. AC

Interaction. 4. Communication with Kuwaitis isn't important but I have quite a bit - professionally and socially. But most of my Kuwaiti friends are quite westernized so they understand where I'm from. DF

5. I don't really make changes. But with one guy, I have to get mentally prepared to see him. He's serious about Islam and we can always enjoy talking about his perspective. I don't know what I do. Sometimes it's a like an English lesson. We've talked about a lot of things but it's just hard to express myself on a deep level. AC

Communication. 6. Myriads [of communication problems] I'm sure. The main thing is never knowing if you're going to be left out to dry. I'm a hopeless optimistic. You really want to believe and trust somebody when they say they're going to do this. I don't think I've figured anything out about it. DF

7. I used to shout a lot but that doesn't work in the Arab world. I learned by experience. I don't shout much. Showing emotion just doesn't affect this place. DF

Stress management. 8. Definitely. Driving [is stressful]. Nothing's being enforced. The police take no responsibility. DF 
9. I don't think I had culture chock. It's never easy moving. Here you're really left on your own. All the sponsor expects to do is pay you. DF

Satisfaction. 10. I've grown an awful lot. I've picked up the computer, done more writing, published. DF

11. The changes in my life are unrelated to the culture. It's the job, having time and money. DF

12. I like being connected to a community and I don't think I'd be that connected in the States anymore. I've done things I've wanted to do for a long time. AC

13. Kuwait's much better than Saudi. It's more open than the compound there. DF

14. I would go to other places in the Middle East which are not so strongly Islamic. DF

Advice. I would hope that they'd be younger. If you want to see the world, it's definitely better to start before you have any roots. And have a plan, whatever it is own a house, whatever. Have very defined goals of what you want out of Kuwait. And no matter how hard it is, you still have a sense of what you're doing here. And you won't be disappointed. You can say you gave it a shot. DF

\section{Subject 15}

The fifteenth subject, a 45-year-old male teacher, had lived in Kuwait for 5 years. He had traveled extensively in Asia and lived 2 years in the Philippines and 3 years in Iran.

Attitude toward difference. 1. As far as media, information - censorship carries the day. Interaction between the sexes is very strictly prescribed behavior that a Westerner would find quite restrictive and abnormal. Academically, there's no motivation to succeed. DF

2. The censorship doesn't get in the way of my life but it does hinder the progress of Kuwait. But I'm a guest here. It's not my place to stir the pot. But I think it's unfortunate that females are not equals. As a teacher, I find them harder working, more capable. 
If they had more opportunity, you wouldn't find the lazy slugs running this place that are. DF

3. They're lazy because education is free. They can't get fired. They have an enormous amount of security and there's no competition, except for influence. DF

4. It's a welfare state and in Western terms, that's not very positive. How does a country better itself? What motivation is there to go out and succeed? DF

5. We live in a crime free environment. In general, I find Kuwaitis far less violent than Americans. People seem more relaxed. And there's a much more positive attitude towards children. Children are a much loved part of life here. AC

6. I miss the opportunity to criticize, basic freedom of speech. We're quite tightly controlled although it doesn't get in the way that often. AC

7. When I leave, I want to get away from Islam, to see men and women laughing together, to see legs not covered in black. I want to relax in ways I'm not able to here. AC

Interaction. 8. Kuwaitis basically control everything I do here. And if they don't, it's Egyptians and they're worse. DF

9. I have some good Kuwaiti friends. They accept me as I am in the same way I accept them as they are. $\mathbf{M}$

10. I don't think being an American has any influence. They care where people are from, but readily distinguish between governments and individuals. If I'm perceived negatively, it's from the standpoint that all expats are perceived negatively. Because this isn't our country. AC

11. I have better friends here than in the States - Americans, Arabs. Maybe it's because everybody's here on a temporary basis. They reach out more. AC

Communication. 12. Good communication is important to me up to the point where I feel I have some control over it, where I think I can do anything about it. But so 
often, it's a one way street in which I'm butting up against a stone wall and then I don't care so much. DF

13. A typically Arab reaction to a request is to say "no" and then think about it. Largely, I think it's the product of Arab personnel management techniques. You don't have a dialog with inferiors. You dictate and it doesn't matter if it's irrational. You have to present that face to the world. Now I just do the opposite. I say "yes" just so they'll leave me alone and make up excuses later. DF

14. I'm definitely more patient. Losing your temper is definitely a dead end. I can smile at people I want to kick in the balls. I guess that's a plus. I saw other people losing their patience and being categorized and never getting out of that first impression. There's definitely a fine line where blowing up like a volcano serves it's purpose. But if it's someone who can make my life miserable, I keep my patience. DF

15. I strongly agree that the tendency to say what you want to hear takes over what is really felt. I generally think that you hear what you want because that person is too chickenshit to tell you to your face. It makes me feel I'm being lied to. DF

16. I can basically interpret from an Arab's mannerisms whether things are going my way or not, regardless of what they say. The mouth can be saying one thing and you need these nonverbal signals to tell you the mouth isn't telling the truth. DF

Stress management. 17. Not much is stressful anymore. Driving used to be, but I just got used to it. Dealing with utterly apathetic students used to cause me considerable stress, but I just got used to it. I don't see myself as a change agent on any level. DF

Satisfaction. 18. I feel very successful as a father here and it's one of the reasons I continue to stay in Kuwait because my job gives me the time for that. But I feel totally unsuccessful professionally and if I were a workaholic with job related goals, I'd be miserable here because I'm not accomplishing anything. DF 
19. To feel successful, I'd have to see motivated students. I'm past the point where I try to motivate them. If someone really wants to learn, I'll give it my best shot. If all they want is a very mechanical treatment of the syllabus, I'll give it to them. DF

20. I was extremely interested in the Middle East. And the complete package that goes with the job was very attractive. Plus travel and good personal relationships. And I wanted my son to grow up in a cosmopolitan environment. Exposure to languages, lots of different nationalities - I want my son to have a feeling of being a citizen of the world, not just of Denver, Colorado. AC

21. My general level of material comfort is much higher here than in previous situations. The biggest problem with Kuwait is that before oil, there was no country to speak of and everything is new. There's no architecture here more than thirty years old. No culture but the nomadic Bedouin. Here if it's old, [they think] it's worthless and that gets in my way a lot. This is not a typical foreign experience. There's no place to go explore the real ethnic Kuwait, to go see people in a way that has passed on from generation to generation. AC

22. I don't know how it's changed me, but I know it has. That's one of the reasons I'm an expat. I want the influence that comes from living in other cultures. AC Advice. 23. First of all, it's extremely important that you be open and not judge too readily and second, I'd say you need to be self-possessed enough to be sure about yourself in troubled times and you should have systems set up to deal with pretty big chunks of time to yourself. AC 


\section{SUMMARY}

Table II and Figure 2 which follow summarize the findings presented thus far. The table indicates subject number, total responses counted, and the percent of responses at various levels of intercultural sensitivity. The figure gives the same information in graph form, with each bar representing the percentage of responses of each subject at a certain level. A word of caution in interpreting both of these relates to the small number of responses counted. Percentages are used for ease of comparison since each subject did not give the identical number of total responses. 
TABLE II

THE SUBJECTS' LEVELS OF INTERCULTURAL SENSITIVITY

$\begin{array}{llllll}\text { Subject } & \begin{array}{l}\text { Total } \\ \text { Responses }\end{array} & \text { DF } & \text { M } & \text { AC } & \text { AD } \\ & & & & & \end{array}$

1

15

$60 \%$

$13 \%$

$26 \%$

2

11

$91 \%$

$9 \%$

3

17

$94 \%$

$6 \%$

4

22

$86 \%$

$14 \%$

5

12

$67 \%$

$8 \%$

$25 \%$

6

13

$15 \%$

$8 \%$

$77 \%$

7

17

$6 \%$

$6 \%$

$82 \%$

$6 \%$

8

19

$100 \%$

9

15

$93 \%$

$7 \%$

10

11

$64 \%$

$36 \%$

11

17

$53 \%$

$6 \%$

$41 \%$

12

21

$62 \%$

$10 \%$

$28 \%$

13

15

$60 \%$

$13 \%$

$27 \%$

14

15

$80 \%$

$20 \%$

15

23

$57 \%$

$4 \%$

$39 \%$ 


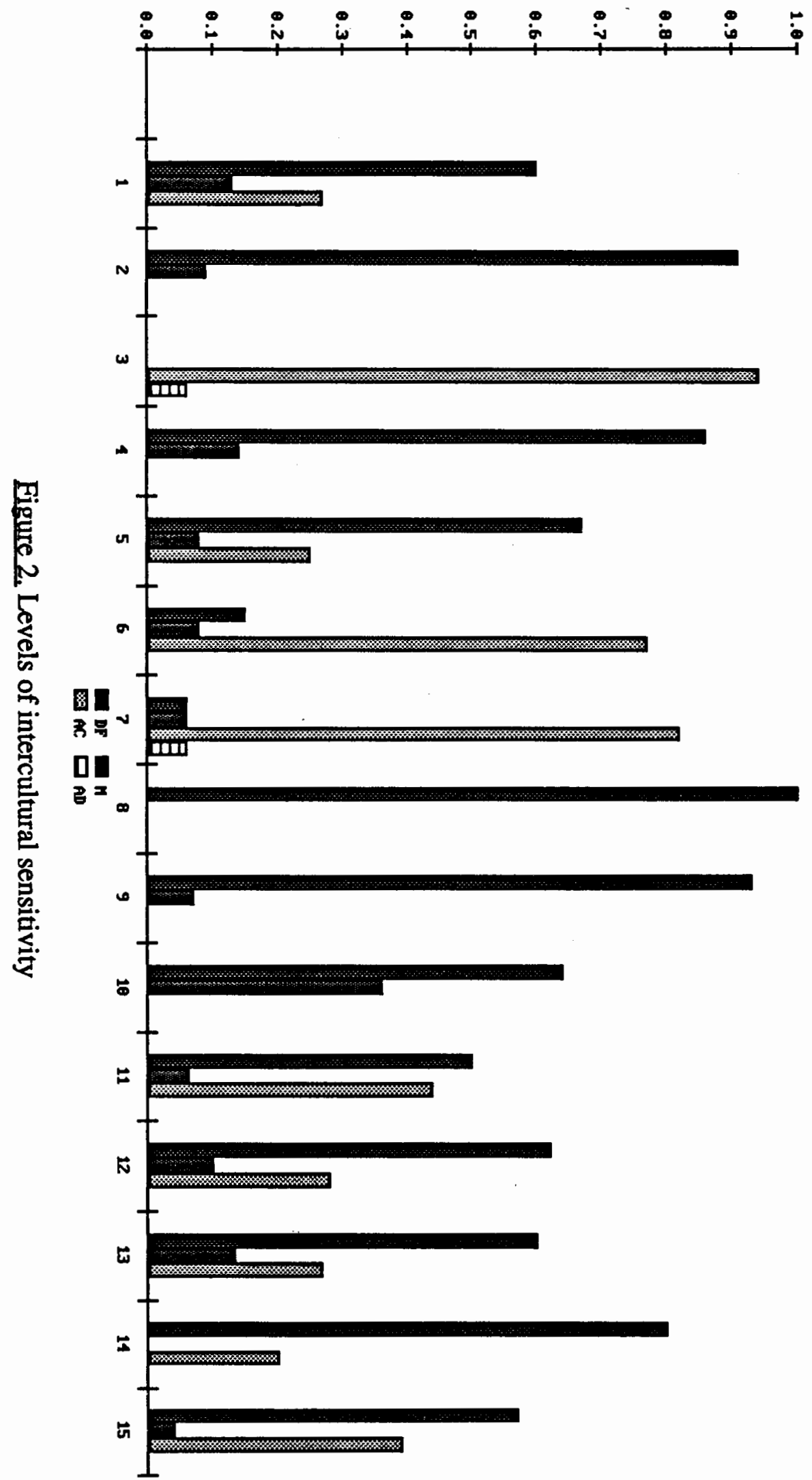




\section{COPING MECHANISMS}

Coping mechanisms employed by the sojourners revealed six themes or basic approaches for dealing with problems encountered in the intercultural situation. These were derived from the questions which asked what the subjects did, as opposed to what they thought, about the differences noted. This section of the paper will address those themes and identify which of them are developmental and which are not.

\section{$\underline{\text { Adjustment }}$}

The most frequently given responses can be called adjustment to Kuwait in terms of modifying certain behaviors to fit the culture of Kuwait. They are not necessarily indicative of adaptation in terms of intercultural sensitivity, however. Many of the changes identified below are indicative of defense. The behavior change is made because it leads to greater comfort and success, but the empathic understanding that would accompany adapting to Kuwaiti culture is absent and frequently accompanied by denigrating attitudes. The broad categories of adjustment which emerged from the interviews

were adjustment in terms of (a) attitude towards time, (b) subject matter, (c) indirect vs. direct communication, (d) patience, (e) dress, (f) male/female roles, (g) personalism, (h) activities, and (i) language.

Attitude towards time. Two subjects mentioned changes in behavior in response to a more relaxed view of time in the Arab world (Adelman and Lustig, 1981; Hall, 1979; Lamb, 1987; Lee, 1980; Marr, 1978; Yousef, 1974). Both said that they were less worried about being on time themselves and one stated that he no longer saw the Arabs as irresponsible or unreliable, believing that the behavior was not directed at him in a personal way. Both of these responses are indicative of developmental adjustment - as change of behavior is accompanied by a nondenigrating change of attitude. 
Subject matter. Four subjects discussed an awareness of appropriate conversational topics and resulting changes of behavior. Two of the answers were indicative of a respect for the differences in sense of humor and the differences in behavior regarding male and female interaction. Two were denigrating - topics of discussion were avoided or changed because of a perceived inability of the Kuwaitis to understand.

Indirect vs. direct communication. Four subjects described behavioral changes made due to the above difference in communication style. Three came to terms with the difference in style and found ways to work with it, such as offering suggestions frequently when it was discovered that questions would not be asked. One recognized the difference, mentioning that he was afraid to "get to the point" and was forced to play a "cat and mouse" game. The behavior changed in accordance with the new rules, but the empathic understanding was absent, limiting the chances of further growth, so this response is called nondevelopmental.

Patience. Six responses related to the necessity for patience in intercultural relations. Three subjects described their initial difficulties but told how they had learned from their experiences a new way of construing the events. One remarked, "When the man says he's going to do it, he'll do it eventually. You've got to have patience." Another said, "When I first came, I'd get upset and think they were being malicious and then I realized that they don't care so I don't either. Now I take a magazine." These changes were in accordance with the norm in Kuwait and accompanied by acceptance at the behavioral level.

Three responses indicated behavioral modifications without acceptance however. All three learned not to express anger, having discovered it was a hindrance to accomplishment of goals rather than a help, but all three described still having strong feelings of anger. "I can smile at people I want to kick," said one. "If you let people butt in front of 
you, you'd get it done eventually," said another. They had learned how to get things done, but resented the need to make the changes.

Dress. Three females mentioned a change of dress style; two mentioned the need to wear less revealing clothing and one the perceived need to "change your clothes to buy a newspaper cause you have to look nice." While none of the responses indicated any attitudinal change, the very fact that cultural differences were noted and accommodated without negative evaluations of Islam or Arab men is a sign of acceptance at the behavioral level.

Male/Female Roles. Five females described modifications made in response to the different sex-based roles in Arab culture. Many males discussed these differences but their reactions were either primarily intellectual, not behavioral, or will be discussed in the category of Avoidance. Three of the responses showed acceptance at the behavioral level, recognizing that conduct that would seem normal and friendly in the United States would be interpreted as "interested" in Kuwait. Two recognized that same difference and modified their conduct accordingly, but expressed resentment at having to do so. These two responses will be labelled nondevelopmental.

Personalism. Five people noted differences in this category. Personalism refers to a communication style in which the personal aspect is as important, if not more important, than the business at hand. The Arab style is generally described as personal, in contrast to the American style, which is described as impersonal (Cohen, 1987; Shouby, 1951; Yousef, 1874). All five responses pointed to the individual's willingness to take the time to "talk about their brother, what I think of Kuwait," "have a cup of tea and then do business very easily," and to "get around and see the people." All five expressed thoughts that there were advantages to this mode of doing business and they appreciated the friendly feeling. These five responses are seen as developmental. 
Activities. Only one person discussed new activities which were culturally bound. Others enjoyed a different kind of social life, but it was related to the expatriate community, not to Kuwait. This response is counted as developmental.

Language. Only two people described learning Arabic as having made a difference in their cultural adjustment. Both said the difference was positive, enabling them to talk to different sorts of people, such as those one might meet at a small teahouse, or generating friendlier responses from Arabs in general. These two responses are developmental.

\section{Tolerate/Accept}

This category differs from adjustment in that the sojourner does not necessarily change his behavior or perspective, but tolerates or accepts the differences observed. Things are not done in a new way, but the way of life in Kuwait is not judged negatively.

Eight responses fit this category. The following quote is representative: "I'm living in their country and if I can't accept their ideas, I don't belong here. Either accept them or just live with them." Responses in this category do not indicate either understanding or lack of understanding of the underlying differences but there is no judgment involved so these are deemed developmental.

\section{Avoidance}

Many people responded to the stress of intercultural living by avoiding stressful situations as much as possible. This seems to work as a coping mechanism, but if employed too frequently, will hinder the development of intercultural sensitivity as most of these behaviors are rooted in defense. The two general groupings were in the areas of communication and stress.

Avoiding communication with Arabs was a surprisingly easy task to accomplish. Most of these answers dealt with awkward, uncomfortable experiences and the desire not to repeat them. "I hate going to their house and feeling awkward and not knowing what to 
do. They won't tell you until after that if you've done something wrong. So then you just feel embarrassed. I don't want to go through that again," said one. Another said, "I feel defensive. I just clam up. I just sit and smile. But I'm starting to turn down invitations. I don't enjoy these things. It's just another wasted evening." One woman said, "I don't want to bridge the gap because I think I would do more harm than good." "We don't see Arabs very often cause it's hard. Their lifestyle is really different. It's hard to carry on conversations." Several responses were in this vein: "I just say, 'Yes, yes' and do what I want. I don't get into it with them. I just avoid it." All ten of the responses in this area are nondevelopmental.

Eight responses mentioned ways of avoiding stress. They ranged from the suggestion that sojourners shop at the Sultan Center \{a large, very modern, American style supermarket\} rather than the souk \{traditional Arab market\}, to a refusal to continue to study Arabic as Kuwaitis were "so insular." All of these responses are labelled nondevelopmental.

\section{Pleasures not Related to Kuwait}

Many people coped with the pressures of life in Kuwait by finding things in Kuwait that entertained them. This is consistent with several authors (Dinges, 1983; Kealey and Ruben, 1983) who suggest that finding enjoyable activities in the new environment is a sign of adaptation. While these activities were related to an aspect of life overseas, particularly the expatriate community, they were not related to anything particular to Kuwait or its culture.

Seven subjects talked about things they enjoyed which ranged from theater groups to research. These are not nondevelopmental in and of themselves, but the statements accompanying them were often derogatory. "The expat community is really very friendly and very close. Maybe it's because the Kuwaiti community doesn't make us welcome," commented one woman. Another said, "I'm doing research on my own. If I didn't have 
that, there wouldn't be any reason to stay here." Others were not denigrating, but indicated little interest in the host community in statements such as these: "I'm very happy here, but it has little to do with Kuwait. I have more time for me than I've ever had." "The Western community is large enough that you're going to find someone you enjoy." "The friendships with other Americans have been the most satisfactory thing about being here." Ethnocentric and ethnorelative sojourners alike enjoyed the many advantages of the expatriate life and making the most of these is positive in terms of stress management. The statements from this study which fit this category, however, were accompanied by statements which were either derogatory or isolationist and are therefore labeled nondevelopmental as they do not lead to development on the scale of intercultural sensitivity.

\section{Expressing Frustration}

Only one interviewee dealt with stressful situations by giving vent to frustrations and anger. Many claimed to have had many angry moments initially but stopped displaying anger when they realized that it made the situation worse. (This was discussed under Patience, in the section on Adjustment.) This particular subject said she had always been very direct so, when an Arab colleague helped her set up her office, she "told him [she] hated it." In the beginning, life in Kuwait was interesting and fun, but after two years, "[I] can't stand it." She was unhappy with the social situation and said, "I don't know how Westerners live with this group/individual stuff. No personal freedom - I just don't like it." Perhaps few would agree that this sojourner was coping at all, but since she had lived in Kuwait for two years in this manner this paper will take the position that this nondevelopmental response was her method of coping.

\section{Conscious Non-Adaptation}

Several female sojourners said they were aware of the differences; they understood both the expected behavior and the reasons for it. In certain circumstances, how- 
ever, they chose to ignore the cultural norms and suffer the consequences, if any. While not all of the behaviors discussed were specifically related to male/female roles, perhaps females were more aware of how different their behavior was as the contrast between American female behavior and Kuwaiti female behavior is greater than the contrast between American male behavior and Kuwaiti male behavior.

The six responses showed varying degrees of awareness. One woman said, "When I came here, I used to dress like a nun, and now I don't. I dress however I want." Another said, "I used to drive my car to a stop sign and not get in the middle lane so that I wouldn't have two men staring at me. But suddenly, I just stopped caring about it. I do a lot more what I want." And another, "I know I'm supposed to have greetings and talk about things, but I still forget. And sometimes I can't be bothered." These decisions do not indicate a deep understanding of Kuwaiti culture (nor do they necessarily indicate a lack of understanding, however).

Other more thoughtful replies showed careful evaluation of the situation:

I don't have the language, but I don't think that excuses me from trying to communicate culturally, from having an awareness of what is and is not offensive. And then I can choose whether or not I choose to offend. Sometimes, I just don't care, but you need to have that awareness.

Another listened to friend who told her what women do and do not do for themselves: Although you may be perfectly capable of doing it, culturally you shouldn't. I moved my own desk drawers and this young man came in shocked and asked me what I'd done. Things like that, I can make a choice, to be culturally appropriate and wait for someone else, or just do it myself. And let them think what they want.

All of these responses will be classified as developmental. None of the respondents indicated negative evaluations of Kuwaiti culture when explaining their choice not 
to conform. The understanding of their behavior, the awareness that was expressed when they made their choices indicates room for growth.

\section{Summary}

The percentages of developmental and nondevelopmental responses are summarized in Table III below.

TABLE W

DEVELOPMENTAL AND NONDEVELOPMENTAL COPING MECHANISMS

\begin{tabular}{|c|c|c|c|}
\hline Subject & $\begin{array}{l}\text { Total } \\
\text { Responses }\end{array}$ & $\begin{array}{l}\text { Percent } \\
\text { Developmental }\end{array}$ & $\begin{array}{l}\text { Percent } \\
\text { Nondevelopmental }\end{array}$ \\
\hline 1 & 7 & $43 \%$ & $57 \%$ \\
\hline 2 & 6 & $33 \%$ & $66 \%$ \\
\hline 3 & 2 & $100 \%$ & \\
\hline 4 & 5 & $60 \%$ & $40 \%$ \\
\hline 5 & 4 & $75 \%$ & $25 \%$ \\
\hline 6 & 3 & $100 \%$ & \\
\hline 7 & 6 & $83 \%$ & $17 \%$ \\
\hline 8 & 6 & $17 \%$ & $83 \%$ \\
\hline 9 & 4 & $25 \%$ & $75 \%$ \\
\hline 10 & 5 & $80 \%$ & $20 \%$ \\
\hline 11 & 5 & $60 \%$ & $40 \%$ \\
\hline 12 & 4 & $50 \%$ & $50 \%$ \\
\hline 13 & 4 & $25 \%$ & $75 \%$ \\
\hline 14 & 1 & $100 \%$ & \\
\hline 15 & 2 & $100 \%$ & \\
\hline
\end{tabular}




\section{CHAPTER V}

\section{DISCUSSION AND INTERPRETATION}

In the previous chapter, the information gathered in the interviews was coded and summarized in percentages, indicating the percentage of responses at each level of intercultural sensitivity for each individual in the study. The coping mechanisms were also coded and presented in a table which summarized the percentage of responses which had been classified as developmental or nondevelopmental.

This section of the paper discusses the results and attempts to explain the outcomes in terms of expectations based on the review of the literature and the model itself. It deals with the many variables that could account for the range of responses and the consistencies and inconsistencies that arise.

\section{LEVELS OF INTERCULTURAL SENSITIVITY}

The first research question concerns the descriptive value of the model. The results appear to justify its use as a descriptive tool. The findings are far from random; 14 out of 15 interviewees are clearly in a particular developmental stage with over half of the responses of these 14 subjects being classified as indicative of a certain level. For 13 of the subjects the percent of responses in a given level was over 60 percent. The remaining subject, referred to as subject 11 in the previous chapter, is more evenly divided between two levels with $\mathbf{5 0}$ percent of the responses at one level and 44 percent at another.

Several trends in the findings merit discussion. One noticeable pattern is the complete lack of response in either the Denial stage or the Integration stage, the levels 
which represent the two extreme ends of the developmental continuum. No subject answered any question in either category.

The absence of Denial is not unexpected in this study. According to Bennett (1986), Denial implies the failure to recognize difference caused by isolation or rejection. It is perhaps unreasonable to expect to find it among sojourners who have lived in the intercultural setting for a minimum of two years. Foreigners did not live in compounds in Kuwait, but in ordinary neighborhoods and while there were many ways to avoid participating in the culture it would have been impossible to live there without noticing some of the more obvious differences. The most Western of all the supermarkets was full of Kuwaitis, most of whom wore dishadashas \{the white robe for men\} or abayas \{the black robe for women\}. No one lived out of hearing of the local mosque which loudly announced the call to prayer five times daily. This study was done on a very specific population in a specific setting rather than a broader group in a variety of settings. It seems fair to suggest that this level is not relevant in this setting, not that this level fails to describe a very real stage of development.

The failure to find any Integration is more puzzling however. While Denial seems unlikely in the intercultural setting, Integration seems more probable in this setting than in any other. A sojourner at this level has integrated varied cultural contexts into his or her sense of self and the intercultural situation would seem to provide the best opportunity for this.

There are several possible explanations for this outcome. One possibility is that the model itself is not descriptive, that the category of Integration is not well defined. A more probable explanation is a shortcoming of the interview schedule itself. The responses were much more difficult to code at the higher levels and after many hours spent in coding, the researcher must conclude that the questions did not demand expression of Integration. While there were opportunities for such statements, the questions did not call for responses that would clearly differentiate between the ethnorelative stages. Without 
any clear support that the statements were indicative of Integration rather than Acceptance or Adaptation, the responses were coded as either of the latter.

An additional possibility is related to an aspect of Kuwaiti society itself. Several subjects commented that Kuwaitis were unwilling to make them part of their community, and that Kuwaitis were not interested in communicating with Americans. While the researcher does not support this assertion, vastly different patterns of social interaction could lead to this interpretation. For example, the author observed that it is very unusual for men and women to socialize together outside the family group. It is the norm, on the other hand, in American society. Kuwaiti families would have been offended had a Kuwaiti insisted on breaching the rule of conduct with American friends, and many Americans would have been offended, or at least very uncomfortable, had they been asked to follow the custom. Such difficulties led to many Kuwaitis having friendships with foreigners that were entirely separate from their family lives.

Eleven of the 15 subjects expressed feelings that relate to the above. The comments ranged from angry descriptions of Kuwaitis as arrogant and insular to a more sympathetic statement in which Kuwaitis were described as a "little bit more standoffish [than other Arab groups] but very willing to help." Finally there was an empathic statement in which the male subject recognized that his being single in a building with families had probably led to suspicions that could never be completely overcome.

In addition, some research supports the notion that, especially in the traditional Gulf countries, sojourners are expected to keep a distance and thereby avoid undue influence on the local culture. Sieveking and Marston (1978) reported a caution given by Middle Eastern colleagues:

Americans should not overemphasize making friends at the expense of firm and efficient delivery of expertise. That is, we [Americans] are employed to produce, 
not solely to be gracious. We are asked to accept the culture of the foreign country but not blend into it completely (p. 20).

Recent events, ranging from the experience of U.S. troops in Saudi Arabia to antiAmerican demonstrations throughout the Arab world, suggest that the influence of Western culture on Arab culture is not always viewed positively and there is considerable resistance to it. Nydell (1987) observes s common Arab perception that, "Indiscriminate imitation of Western culture, by weakening traditional family ties and social and religious values, will have a corrupting influence on Arab society," (p. 18). The author of this study believes that the Kuwaitis' fierce determination to hang on to valued traditions and a view, held by politically powerful conservative elements, that Western culture corrupts could account for the failure of any Americans in this study to have achieved a depth of understanding of the culture sufficient to have incorporated it into a new frame of reference.

Another surprising result is the limited representation of the category of Adaptation in this population. This is even more unexpected than the lack of Integration as Adaptation should not be so hard to achieve. Again, it could be that the model fails to clearly define the level. As mentioned above, the researcher had difficulty coding responses at the ethnorelative level. The statements were clearly not ethnocentric, but it was difficult to differentiate between Acceptance and Adaptation. This is, again, most likely the fault of the questions themselves, which failed to demand statements which would make the distinctions clear. Thus, it is possible that there are a higher number of individuals at this level than those who were categorized as such. This would not, however, affect the overall finding that the model is indeed descriptive. The majority of the responses were in the category of Defense and there was little difficulty discerning the difference there.

A finding which was contrary to expectation is the small percentage of responses which are representative of Minimization. Sojourners at this level compare cultures in 
terms of similarities and hold the view that we are all basically alike. Since the model is proposed as a continuum, one would expect individuals to move through it in stages. The findings do not support this. Not only did very few subjects indicate thinking in terms of Minimization, many subjects skipped the level altogether, showing strength in both Defense and Acceptance, but little in between.

This could be a failure of the model. It is possible that the category is not welldefined. The responses which were coded as Minimization so clearly fit the model however, that this does not seem likely. Comments such as, “I don't think I've changed. I've been myself," and "People are people and people are going to do what people do - good guys and bad guys," clearly support the existence of thinking at the stage of Minimization.

Perhaps the conditions in Kuwait once again account for the relatively few responses at this level. Differences were apparent everywhere and even though many commented on how boring Kuwait was because it lacked observable traditional culture (all the buildings were modern, and daily life was not very exotic on the surface), only one subject in fact failed to describe the differences as vast. This subject (Subject 10) is the only one whose responses were predominantly in Minimization.

Aspects of the subject population could also have a bearing on this outcome. The population itself was well-educated. All had received college degrees; nine of these had completed Master's Degrees. Most of them indicated that they had read about Arab culture at some point, talked about it with compatriots and Arabs alike, and compared their experiences to what they had discovered in reading and discussion. Given the differences between American and Arab cultures noted by researchers and described in Chapter II, perhaps it is improbable that well-educated sojourners would conclude that we are in fact all the same.

This possibility is borne out by the findings of this study. The interviewees were aware of the differences and articulated them well. The contrast between the interviewees 
was not whether or not they perceived the differences, but in the manner in which they judged them. This accounts for the subject (Subject 11) who was almost evenly divided between Defense and Acceptance. She remarked several times about how enlightening a book, The Arab Mind, had been in terms of what she found in Kuwait. She was lucid about the differences and either judged them negatively or was able to accept them. Nothing in her experiences had led her to conclude that we were in any way the same, an idea which she stated very clearly in the following quote: "Before I came, I had this notion that underneath people really are the same and since I've been here, that's absolutely not true...Y You need food, water, sleep, but there it ends."

Thus, it is possible that in certain intercultural contexts this category is not a likely result. It seems reasonable that those who cannot fail to notice difference, like the subjects of this study, would evaluate it in some way. As shown here, they either come to terms with it and are able to accept it at a certain level, or they reject it.

An expected, though disappointing, result is that the majority of the interviewees can be described as ethnocentric, falling predominantly into the category of Defense. Ten of the 15 subjects indicated Defense in over half of their responses. Why do so many people who are for the most part not unhappy in their sojourn continue to perceive their hosts in such a negative way? Again, current events have highlighted and brought to national attention the differences that separate Arabs and Americans, but it is surprising that so many who have lived and prospered in a country should have such ethnocentric ideas.

Perhaps the answer lies in the differences themselves. A review of the interviews reveals many differences that seemed to provoke a great deal of antagonism. The group/ individual differences, male/female roles, the importance of status or "face," and the effect of Islam, all referenced earlier, seemed to generate the strongest feelings.

Many commented on the importance Kuwaitis placed on the group, particularly the family. The strong family ties were described as "debilitating" by one subject. An- 
other said, "The individual is always sacrificed for the family, the society. [There's] a suppression of individual creativities." "It's this group-individual stuff. It really bothers me. In the U.S., there's a stress on the individual - you know, you make yourself what you are. Here, the group makes you what you are," commented another. Very strong feelings were expressed by one who said:

They say an Arab family is so united, but I wouldn't put it past somebody to pull the rug out from under their father if it meant money. We don't know about them. We don't go to their houses. They come to ours. I think it's their tribal sense of family. They don't trust me, so why should I trust them?

The above interviewees clearly place a high value on individualism and were unable to accept cultural values in such contrast to their own.

Another area of difference that generated a lot of comment was the role of women. One female subject said, "I think it's just awful here, especially being a woman. I'm tired of not being able to look people in the eye or sit where I want on the bus." Another female felt she couldn't "get close to a Kuwaiti woman because they see me doing things perhaps they'd like to do." Another self-described feminist said, "I don't agree at all that women are on pedestals...that they get privileges. I don't think they get deference." These women, who were all Defensive, continued to judge Kuwait by their western standards and did not like what they saw.

The importance of status induced many negative reactions also. According to one subject, "Kuwaitis are after big desks. There's no concept of professional standards. Kuwaitis earn their positions by sitting there." A teacher said, "[Parents] don't care if a kid has knowledge. They just want the grade."

Finally, though no one directly criticized Islam, there were negative statements about its effects. The religion is described as "stifling," and "one of a lack of free will [and] thus a lack of responsibility [which] shows up everywhere." Several responded that 
their first choice when planning a holiday was to go anyplace that was non-Muslim. Among the subjects of this study, Islam is widely perceived as an institution that infringes on personal freedom, an often mentioned aspect when subjects were asked what they missed most about their own culture.

It is possible then, that the particular value differences which are dissimilar in Arab and American value systems are ones which are often supported most strongly and thus are the most difficult to evaluate nonjudgementally. It seems that the subjects perceived a challenge to something which they valued very highly and most remained defensive about it throughout their sojourn.

Another possibility which arises is the possibility of choice. The results of this study indicate that enhancing intercultural sensitivity is not a central goal of the sojourn for all sojourners or hosts. As Subject 11 noted, "Kuwait is there if I want to experience it, but not get involved." It is possible that some sojourners choose pursuits in their sojourn which do not necessarily lead to enhanced intercultural sensitivity, but do lead to accomplishment of personal goals.

\section{Interaction}

Many researchers supported the significance of interaction with the hosts as a major factor in intercultural adjustment (Gudykunst, Wiseman, and Hammer, 1978; Benson, 1978; Brein and David, 1971). Church (1982) believed that the nature and extent of social interaction might be the most important factor in evaluating sojourner adjustment. While some studies Church reviewed supported the "association hypothesis" which states that more interaction with hosts is related to more favorable attitudes towards them, Church found that too simplistic. He suggested the "modified culture contact" hypothesis. This relates increased interaction to more favorable attitudes which in turn lead to better personal adjustment. This is reciprocal — better adjustment leads back to more interaction, thus creating a positive spiral. 
The probability of this is supported by this study. Eight subjects (Subjects 1, 2, 4, $5,8,9,11$, and 12 ) reported limited, primarily work-related interaction. All of these subjects were predominantly at the Defense level.

A related area is the motivation to communicate, a subject Dinges (1983) believed should be examined in greater depth. In this study, the association between reported interaction and motivation provides interesting results. Eight subjects said they had no motivation to have good communication with Kuwaitis. Of these eight, five (Subjects 1, $2,5,9$, and 11) also reported limited interaction. This is also reciprocal. The connection of no motivation and limited interaction created a negative spiral. It is not surprising that all five of these subjects were Defensive overall.

More interesting are the three subjects (Subjects 4, 8, and 12) who expressed a high motivation to communicate with Kuwaitis but reported limited interactions. All three were very disappointed that the relationships they had anticipated had not materialized and all three blamed the Kuwaitis' lack of interest in interaction for the gap. The following response is typical of this idea: "I would've loved to have been integrated with Kuwaitis but I just wasn't welcome."

The remaining group (Subjects 13, 14, and 15) also present an interesting incongruence. All three reported no motivation to have good communication with Kuwaitis yet they recounted a great deal of social interaction. All had good feelings about those they considered friends but when asked about Kuwaitis as a group, friends were not the ones mentioned. All three described Kuwaitis they might encounter in a work or business situation when discussing their own lack of interest in communicating. This could well be an example of what Barna (1976) described when she discussed preconceptions and stereotypes. In these cases, the friends were considered exceptions to the rules and negative evaluations were not altered by these experiences. There is no positive spiral from the high level of interaction without the accompanying positive attitude. 
Only four subjects (Subjects 3, 6, 7, and 10) reported both high motivation and high levels of interaction. These 4 were the only subjects of the 15 that did not fall into the category of Defense. For these sojourners, there is a relation between high interaction and adjustment. It is not clear which came first, a positive attitude or high interaction, but it supports Broome's (1985) conclusion that while positive social interaction does not assure successful adjustment, adjustment is unlikely without it.

\section{Communication}

The answers to questions relating to the subjects' understanding of communication problems and differences in communication style were less informative. The subjects exhibited a wide variety of opinions as to what constituted a communication problem and had trouble understanding what was meant by communication styles. Four discussed communication problems as language problems which had either been helped by studying Arabic or could not be helped because of the lack of it. Two subjects said they were not aware of having any communication problems although their interviews were full of examples. One subject admitted to many communication problems and summed it up with the statement, "They just don't understand what I'm talking about," thus assuming no responsibility for the misunderstandings.

The remaining subjects recognized that they had communication problems at various times. The four subjects who were not categorized as being in Defense were not the only ones to demonstrate a clear understanding of their communication difficulties. However, it is notable that all four (Subjects 3, 6, 7, and 10) showed a good understanding of the nature of their problems and were able to discuss solutions they had found. This suggests that an understanding of communication differences does not necessarily lead to intercultural development, but development is improbable without it. 


\section{Stress Management}

The answers regarding stress did not in general discriminate between those who were ethnorelative and those who were not. Three subjects recounted very little daily stress, seven mentioned only driving as a stressful activity, and one encountered some work related stress. Only four (Subjects 1, 2,8 and 12) said that many aspects of daily life were stressful. All four were predominantly in Defense.

Some authors (Brislin, 1981; Hammer, Gudykunst and Wiseman, 1978) have included the ability to cope with stress as a major factor in adjustment or intercultural effectiveness. These results do not support this assertion. While the subjects who did experience a great deal of stress were all at the level of Defense, many other subjects at this level reported little or no stress. This suggests that a great deal of stress is indicative of ethnocentrism and a failure to adjust, but that very little stress is not necessarily indicative of the opposite, ethnorelativism and adjustment. This leads to a question which will be discussed again later: Is intercultural effectiveness necessarily tied to intercultural sensitivity?

A more applicable theory is the uncertainty reduction strategy of adaptation discussed by Gudykunst and Hammer (1987). Three of the four patterns they described are reflected in the data. High uncertainty coupled with high anxiety describes the four who acknowledged considerable stress. They did not understand the environment and a great deal of tension was the result. The three ethnorelative sojourners (Subjects 3, 6 and 7) could represent the other end of the scale. They may be described as exhibiting low uncertainty and low anxiety. Their understanding of the surroundings led to a reduction in stress. Subject 10, the only subject in Minimization, may lack the understanding, but she felt so comfortable in an environment which she perceived as so like home that she had little anxiety. The remaining subjects may represent a third part of Gudykunst and Hammer's (1987) spectrum. They had "adapted" and felt at ease in the intercultural 
setting but had not necessarily acquired the understanding that accompanies ethnorelativity.

\section{Culture Shock}

The answers concerning culture shock revealed widely varying ideas of what constitutes culture shock. Three sojourners reported having no expectations and experiencing no culture shock. Another three reported having no expectations but experiencing culture shock. Four said that they had had the wrong expectations and experienced some culture shock and five thought that some preparation had lessened the culture shock.

Some of the defense mechanisms mentioned by Barna (1983) such as hostility and rationalization were noted, in addition to the feelings of disorientation and loss described by J. Bennett (1977) in her discussion of transition shock. It is likely that the problem was confusion as to the definition of culture shock, rather than an inconsistency in the subjects' experiences.

\section{$\underline{\text { Satisfaction }}$}

The first question in this topic area dealt with the interviewees' perceptions of success in their roles in Kuwait. Ten of the 15 subjects reported feeling successful. The four non-Defense subjects are among these. Only one subject (Subject 9) said she did not feel successful while the remaining four reported mixed feelings. While the study cannot affirm how successful the subjects truly were, the fact that they had all completed a minimum of two years indicates that the employers were pleased with their performance and that they were, to some degree at least, successful.

In answer to the question regarding satisfaction with the experience overall, all 15 subjects replied that they were satisfied. The reasons for their satisfaction vary, but for the most part, the sojourners were satisfied because living in Kuwait had allowed them to accomplish personal goals. The three most commonly mentioned were the opportunity 
to save money, the chance to travel, and experience on the job. Friendships, pursuit of hobbies, a relaxing lifestyle, time with family and time to pursue writing were also cited as benefits of the time spent in Kuwait. Two sojourners appreciated the broadening of perspective the intercultural experience allowed, but both subjects (Subjects 2 and 15) were predominantly in Defense. Only two subjects (Subjects 3 and 7) stated that the intercultural experience was the primary explanation for their overall satisfaction. Both of these subjects were predominantly in Acceptance.

These findings are supported in the literature as far as the relationship between feelings of success and feelings of satisfaction. Hammer, Gudykunst and Wiseman (1978) believed that people who felt satisfied also felt that they had performed well. It was therefore presumed that they had been successful. The congruence between perceptions of success and feelings of satisfaction in this study corroborates this. Benson (1978), Brislin (1981), and Church (1982) agreed that satisfaction was a significant dimension of adjustment, and according to Kealey and Ruben (1983), a major factor in intercultural effectiveness.

Dinges (1983) discussed social behaviorism in relation to intercultural competence. According to this theory, an adapted individual is one who has found reinforcers in the new environment. All of the subjects appear to have been successful in this regard. All 15 had found more than one aspect of life in Kuwait that was personally rewarding and resulted in satisfactory feelings overall. Once again, this gives rise to the question concerning the connection between intercultural effectiveness and intercultural sensitivity. According to the above interpretations of intercultural effectiveness and adjustment, most of the sojourners were both effective in and adjusted to the intercultural environment. Few of the sojourners' experiences, however, represent growth in intercultural sensitivity.

This could suggest that too much has been made of the connection between intercultural sensitivity and adjustment. As discussed in Chapter II, Kealey and Ruben 
(1983) found complete agreement in the literature on the importance of empathy, respect, interest in the local culture, flexibility and tolerance in determining adjustment. However, most of these sojourners clearly functioned well according to their own and the hosts' standards. They were sufficiently content with their lives and described many advantages. Yet, only 3 of the 15 subjects, or 20 percent, were categorized as ethnorelative. Very few demonstrated an abundance of the characteristics most often listed in discussions of intercultural success.

Is intercultural sensitivity as imperative to adjustment as the literature has maintained? As suggested by the author in Chapter $\Pi$, it would seem that intercultural sensitivity is not the same as adjustment, but, instead, a possible element of adjustment. As Benson (1978) said, "it may be necessary to look at specific cross-cultural situations and determine criterion dimensions relevant to them, such that there are as many kinds of overseas adaptations as there are cross-cultural situations" (p. 32).

\section{Interaction of the Individual and the Environment}

According to Dinges (1983), "The person is in dynamic interaction with the social environment" (p. 184). People do not act in a vacuum. Therefore, all of the reactions described above must be considered in terms of the context of the intercultural situation. This study, like most studies of adaptation, has examined those individuals already in the cross-cultural situation and thus the effect of the environment cannot be separated from the individual variables.

A further examination, then, of the situational variables particular to Kuwait may provide greater insight. Brislin (1981) defines situations as external factors which individuals must deal with to achieve a goal. They are environmental factors which combine with the individual's characteristics to determine behavior. These factors provide a critical context for the behavior. 
Of the seven variables he discussed, the author found four to be of particular relevance to Kuwait. The amount of structure is one variable he described. In a structured situation, the expected behavior is clearly defined and accepted. Eight of the subjects said this was true of their experience in Kuwait, but seven said it was not. Both ethnorelative sojourners who were working for non-American organizations reported that an unstructured situation was the norm for them, but that did not cause undue stress. Both described ways of working in the situation which allowed them to accomplish their goals. The other five who described a lack of structure found it very confusing and described the Kuwaitis as inefficient and frustrating to deal with.

The presence or absence of a niche is a contributing factor. By this, Brislin (1981) means a role which gives satisfaction to the sojourner and fulfills a need of the hosts. Those without a niche may feel their expertise is unused or that they don't possess the expertise required. Ten of the interviewees gave replies indicating that they felt they had a niche - they felt successful themselves and were sure that they were delivering what was expected. All of the non-Defensive sojourners were in this group. Two subjects did not address this at all and three subjects felt unappreciated by the hosts, principally in the work setting. They made it clear that this contributed to negative feelings overall. All three of these subjects were teachers and all three were predominantly in Defense.

This is related to another variable mentioned by Brislin (1981) - the presence of ascribed power. This describes a situation in which the sojourner, often from a wealthier country, is deferred to and treated as though he had a great deal of power. Americans in Kuwait were not sojourners from a wealthier country, a situation unlike most of the previous overseas experiences reported by the subjects. The author observed that Americans were not treated with undue deference in the way that many who have traveled in the developing world have come to expect. It is possible that unmet expectations of 
esteem led Americans to conclude that Kuwaitis were arrogant, when, instead, Kuwaitis were for the most part merely treating the American sojourners as equals.

Relevant to this is the question in which sojourners were asked if they felt they were perceived positively or negatively as Americans. Seven of the 15 felt that Americans were well-liked in Kuwait. Three of the non-Defensive sojourners were in this group. Two, including the remaining sojourner in Acceptance, believed being American had no effect on how they were perceived or treated. Six, all teachers, expressed negative feelings, saying that Americans were not respected or liked in Kuwait.

In general, teachers did not perceive that they had much status in Kuwait, a situation not unlike the United States. Nine of the subjects of this study were teachers and two were librarians, making a total of 11 subjects involved in the field of education. Therefore, it is possible that many shared at least in part the sentiments expressed so vehemently by Subject 9 when she said, "English teachers are treated like second class citizens....Feeling like it's not respected makes me wonder why I'm doing it." She also commented, "In Japan, the salary wasn't much more, but there was a lot of prestige. I don't like to say I work for the (Kuwait Oil Company) Training Centre." Subject 12 echoed similar frustrations when he commented, "I put in more time and effort than anyone else in the whole department [but] there is no gratitude, no appreciation."

Sojourners who do not get the deference they expect as Americans in the "third world" and who also feel that their job denies them status are likely to be dissatisfied. In fact, all but one of these teachers was predominantly in Defense. The teacher who was not (Subject 7) had lived in Kuwait for nine years and spent only two of them connected to the expatriate community. He commented that one of the things he liked most was going to small Arabic cafes where he could sit and talk with the people of the neighborhood. His goals and pleasures implied little interest in status. The other three non-Defensive sojourners (Subjects 3,6, and 10) held high-status positions and, while only the 
diplomat described situations where he was held in higher regard than he perhaps deserved, none called the Kuwaitis arrogant or felt under-appreciated.

A final variable suggested by Brislin (1981) is termed consequences for self and others. Some sojourners' responsibilities may require so little interaction with hosts that there may be few consequences of behaviors not task-related. Although most of the subjects in this study were in professions that require interaction, few were required to learn new rules of conduct consistent with Kuwaiti culture as many of them operated an American work environment, i.e., the U. S. Embassy or The American School of Kuwait. Their social lives were centered around other Western sojourners. There were so many Westerners that sojourners could transport American values and habits, encountering occasional frustration, but rarely feeling the need to make major changes. The consequences of their behavior in terms of intercultural communication can be described as minimal.

An additional factor lies in the Kuwaitis themselves. The researcher was often told that her habits and way of life were all right because she was an American. The Kuwaiti males would not have liked their sisters or wives to teach all-male classes, but even the most conservative stopped short of judging the author personally. This kind of open-mindedness allowed a certain kind of freedom from rules, both the constraints of the home culture and of the new culture. More than one sojourner recounted this as a major advantage of expatriate life and, while it made life in Kuwait more comfortable for many, it did not enhance the development of intercultural sensitivity as so little sensitivity (as defined by Bennett, 1984) was required.

\section{Demographics}

The demographic information summarized in TABLE IV on the following page reveals some interesting patterns. The status of the sojourner's occupation seems to have a bearing on adjustment as discussed above. Gender may also be a relevant category in the Arab world. Although 8 of the 15 subjects were female, none of them was categorized 
as ethnorelative. Only a female with a high status job was in Minimization rather than Defense. The perceived difficulties of being female in Kuwait as previously discussed in this chapter most likely account for this result.

\section{TABLE IV}

DEMOGRAPHIC INFORMATION

Subject

Age Occupation

Sex

Previous Exp.

35 Teacher

M None

2

30 Teacher

F None

3

48 Diplomat

M 20 years

4

32 Teacher

F 2 years

5

35 Teacher

F None

6

35 Engineer

M 7 years

7

35 Teacher

M Travel

8

27 Librarian

F 1 year

9

45 Teacher

F 3 years

10

53 Bank analyst

F Business

11

37 Librarian

F Business

12

54 Teacher

M 5 years

13

40 Teacher

F $21 / 2$ years

14

35 Teacher

M 2 years

45 Teacher

M 6 years 
As was expected, previous overseas experience did not in fact discriminate between those sojourners who were ethnocentric and those who were ethnorelative. Although two of the sojourners in Acceptance (Subjects 3 and 6) have the most previous experience, several Defensive sojourners have more experience than the remaining ethnorelative subject and the subject in Minimization. Consistent with the literature, previous overseas experience does not appear to be an indicator of intercultural sensitivity or adjustment. Several subjects in fact compared Kuwait negatively to their previous overseas experience(s) and this comparison hindered rather than helped developmental adaptation.

Included in the demographic section of the interview were questions concerning language. Eight of the subjects had never studied Arabic. Seven had made an attempt, but only one claimed to speak it fairly well (Subject 8) since she had majored in Middle Eastern Studies in college. Three of the non-Defensive sojourners had studied Arabic; the fourth, (Subject 3) a diplomat, said he had never had the time.

At first glance, this would seem to be arrogance on the part of the American community. The author found Kuwait to be a very cosmopolitan country, however, and English was the language of business and socializing in the polyglot environment. Even those such as Subject 7 who made great efforts to learn the language were frustrated by encounters with Arabs who were even more interested in practicing English. Perhaps it is in recognition of such situations that Kealey and Ruben (1983) talked about interest in the language, rather than language ability, and Gudykunst and Kim (1984) agreed, saying that fluency was not always necessary but that efforts to learn some basics would be appreciated.

Kealey and Ruben (1983) stated that realistic predeparture expectations were one of three predictors of overseas effectiveness. Barna (1976) said that unrealistic expectations were a "stumbling block." The comments and feelings of subjects of this study support this. Only three subjects reported experiences congruent with expectations, and 
one of these had had negative expectations which were, not surprisingly, confirmed. Three reported no expectations at all. The remaining nine found Kuwait quite different from what they had imagined. Four found it more modern than they had expected and five expressed general disappointment in what they had found.

Church (1982) reported that a frequent Peace Corps finding was that morale and satisfaction were higher in rural areas where the indigenous culture was more prominent. This suggests that people who really want to "experience" another culture may not be as happy in an urban setting where cultural differences are less marked. The author's experience in highly urbanized Kuwait supports this. Several of the individuals who were disappointed at what they found compared Kuwait to a Peace Corps experience and found something quite different. The discomfort they felt as a result was labeled a shortcoming of Kuwaiti culture.

\section{COPING MECHANISMS}

Table III, which appears in the Chapter IV, indicates no difference between ethnocentric and ethnorelative subjects in terms of the ability to describe coping mechanisms. Predominantly Defensive subjects are at the bottom (one response) and the top (seven responses) of the scale. The notable difference is in the type of response. The four non-Defensive subjects (or twenty-seven percent of the total sample) accounted for fortytwo percent of the responses classified as developmental. Subjects 3 and 6 gave few responses but one-hundred percent of them were developmental. The remaining subject in Acceptance indicated only one non-developmental response out of six; in other words, 83 percent of his responses were developmental. This suggests a strong relationship between the level of intercultural sensitivity and coping mechanisms employed. The 
relationship is reciprocal; developmental coping mechanisms can lead to greater intercultural effectiveness which results in further developmental behaviors.

The researcher recognizes that "developmental" is not the same for all levels. The same response could represent stagnation in Acceptance but mean growth in Defense. The responses in this study did not lead to this interpretation however. Most of the nondevelopmental responses were judgmental responses which effectively closed the door to deeper understanding. The developmental responses were those which allowed for greater insight and understanding of the differences encountered.

The fact that many Defensive sojourners gave developmental responses suggests several things. One possibility is that the sojourners were in fact developing. It is likely that many of these responses indicate openness and the opportunity for growth which would lead to an eventual movement out of Defense.

Another explanation is that learning to behave in culturally appropriate ways is not sufficient for development. The characteristic lack of empathic understanding which indicates Defense could prevent these subjects from advancing along the continuum. The positive reciprocal relationship described above cannot develop without empathy, limiting the growth potential of the sojourners this describes.

\section{SUMMARY}

Recent literature stresses the importance of culturally appropriate behavior when discussing intercultural effectiveness. Dinges (1983) does not believe that a change of attitude necessarily brings about an improved performance. He suggests intercultural training needs to concern itself more with behavioral outcomes than it has in the past. Gudykunst and Kim (1984) include a behavioral component in their description of successful intercultural communication and Ruben (1977) describes the need for a display of empathy, which implies an action, not just an attitude. 
The findings of this study support this up to a point. All 15 sojourners can be presumed to have fulfilled the needs of the hosts. All had completed contracts and most had extended their stay. In addition, all the sojourners had found some aspects of their stay in Kuwait agreeable and all had rated the experience as satisfactory overall. Ten of the 15 subjects felt successful in their roles and 11 of the 15 were able to go about daily tasks with a minimum of stress. According to much of the literature, all of these are important indicators of intercultural effectiveness. Therefore, it appears that most of these sojourners functioned well at a certain level in this particular setting. The interaction of these individuals with the environment led to a degree of success. But, as noted, most of these sojourners were also ethnocentric.

In certain areas it was evident that the lack of empathy prevented growth. In talking about differences between the two cultures and in discussing levels and types of interaction, the ethnocentric sojourners revealed judgmentalness and a lack of understanding which precluded further progress in terms of intercultural sensitivity. These sojourners were not interculturally effective in the crucial area of interaction. They had learned some behaviors which allowed them to function with reasonable success on a daily basis. But, without the open mind and acceptance of difference so critical in most discussions of adjustment or adaptation, these sojourners were either unable to grow interculturally or had chosen not to pursue it. This study suggests that intercultural sensitivity as defined by Bennett (1986), and as described by the developmental model is an integral part of intercultural communication. In certain situations, certain adaptations which bring comfort to the sojourner and allow the accomplishment of necessary tasks are possible without intercultural sensitivity. The need for such sensitivity varies with the situation and some may be content with behavioral outcomes alone. It appears that the kind of intercultural effectiveness depicted by these subjects is possible without empathic understanding and intercultural sensitivity. As was suggested at the outset of this study, 
intercultural sensitivity is a component of adjustment, but not synonymous with it. Nevertheless, few descriptions of successful intercultural communication are thus limited. This study suggests that the situational variables must be considered when defining intercultural success in a specific environment and that intercultural success as it has been discussed in the past is unattainable without intercultural sensitivity. 


\section{CHAPTER VI}

\section{LIMITATIONS, SUGGESTIONS FOR FURTHER RESEARCH, AND PRACTICAL APPLICATIONS}

Although some of the results were surprising, this study was supportive of the literature for the most part. As the previous chapter explained, the importance of many commonly held factors of adjustment was upheld by the results. However, the relationship between these factors and competence and success in the intercultural living situation was not demonstrated in this study. The meaning, strength and implications of these results must, however, be considered in terms of the positive and negative aspects of the study itself. This chapter will deal with this final aspect of the research.

\section{EFFECTIVENESS OF METHOD}

Naturalistic inquiry appears to have been an effective method for obtaining information for this study. Tucker (1979) described it as a means of studying "phenomena that exist because people define them as real, for example, definitions of situations, socially constructed meanings, or interpretations of events or social institutions" (p. 119). Discovering the "socially constructed meanings" was essential to this research and naturalistic inquiry allowed the subjects to express their opinions and perceptions freely.

Taylor and Bogdan (1984) mention matters to consider when evaluating results obtained in interviews. They caution that since "interviewers do not directly observe people in their everyday lives, they are deprived of the context necessary to understand many of the perspectives in which they are interested," (p. 82). I believe that my membership in the community being studied mitigated some of the negative effects of this. 
Sharing many of the experiences of the subjects and being familiar with the contexts provided the insights necessary for a keen understanding of their remarks.

Being a part of the community also appears to have been an advantage in the interview process itself. The subjects seemed to feel comfortable talking about their experiences with someone they presumed would empathize with them. Most made a point of saying that they had really enjoyed the interview and felt they had learned something themselves.

When designing this study, the researcher was concerned that her membership in the community might have a negative aspect; it was feared that it might make it difficult for the subjects to be honest. The researcher was afraid that, knowing the nature of the study, the interview subjects might tailor their responses to appear more culturally sensitive than they, in fact, were. The high percentage of subjects who were predominantly in Defense suggests that this was not a problem, however.

On the whole, the interview schedule was an effective tool for uncovering the data necessary, although there were a few questions which proved confusing and consequently yielded less useful data. The subjects had no trouble discussing value differences and were not only cognizant of the differences, but appeared to have given them a great deal of thought. They had little difficulty talking about interaction and satisfaction, both in general terms and in detail. Communication problems and differences in communicative style proved very troublesome, however. Few subjects could describe problems they had had, and very few had noticed differences in style. While other parts of the interviews revealed many communication problems and the subjects expressed irritation at differences they had encountered, few related these to intercultural communication.

Culture shock was another area that yielded inconsistent results. The subjects appeared to have widely varying ideas of what culture shock means and their responses to this set of questions contained few worthwhile insights. The researcher had anticipated seeing a connection between culture shock and predeparture expectations but found this 
to be another area which proved difficult to discuss. Many subjects reported having no expectations at all, a statement which seems unreasonable given the enormity of the decision to move to Kuwait.

A helpful element of the open-ended interview schedule was the opportunity for cross-checking and clarification it provided. Many of the subjects answered several questions in response to one from the interviewer. This unsolicited data was useful in the above regard. It also allowed the interviewer to maintain a conversational tone throughout. Although the researcher generally followed the order of the interview schedule, deviations were sometimes appropriate. When a certain question had been clearly answered it was not necessary to ask it in order; the responses were simply labeled by question number at the time of transcription.

\section{LIMITATIONS}

The method employed here is useful and has provided interesting results, but future studies could attain more reliability with changes in the design. One of the limitations of this study is the fact that all the work was done by one researcher, although, in a significant way, this was an advantage. As Taylor and Bogdan (1984) observe, a hallmark of qualitative research is the single researcher who continually refines the interpretations and makes use of the experience with the setting and informants to make sense of the data. Some of the responses are difficult to code out of context and the researcher's knowledge of the people and the setting provided the context necessary. However, Taylor and Bogdan (1984) caution readers to remember the researcher's assumptions and presuppositions when assessing credibility of a study. It is impossible for researchers to avoid a certain amount of bias as researchers bring certain assumptions and frames of reference to the study and the data is unavoidably filtered through these. A single researcher magnifies this problem. 
This is particularly relevant to the coding section of this study. Multiple coders would greatly enhance the reliability of this study. As it is, this study relies on one person's understanding of the levels, and the same person's interpretation of the results.

For example, the researcher had problems determining which responses were indicative of Acceptance as opposed to Adaptation, or Integration. As suggested in Chapter V, it is likely that the questions failed to demand responses which would make the distinctions clear. An additional coder would have been extremely helpful in this case, to either note the differences or confirm the lack of evidence present.

A second limitation is the sample, both the small size and the fact that it is not random. Due to the time-consuming process of interviewing, transcribing and finally, coding, the researcher completed 15 . A random sample would have been possible only with official records of Americans residing in Kuwait and the researcher did not have access to these. As mentioned in Chapter III, this does not compromise the research questions in this study, but it limits the inferences that can be drawn. These results cannot be generalized to the American community in Kuwait as a whole.

Another aspect of interviews Taylor and Bogdan (1984) talk about is the "discrepancy between what [people] say and what they do" (p. 81). As the authors say, one may gain insight as to how people perceive the world from the self-reports, but this may be quite different from the way in which they behave. In this case, the majority of the subjects reported feeling successful in the intercultural setting and while this is an indication of their perceptions, it is not an indication of their actual success. Perhaps these subjects were having a great many problems which they were unaware of. It is also possible that these unseen problems account for many of the negative feelings directed toward Kuwait and its culture. In summary, because the interview does not allow the researcher to independently confirm the statements made, the results may be misleading and this possibility must be considered when evaluating the data. 
Particularly relevant to this study is another observation made by Taylor and Bogdan (1984):

People say and do different things in different situations. Since the interview is a one of a kind situation, one must not assume that what a person says in the interview is what that person believes or says in other situations (p. 82).

The topic of the interviews was the subjects' views of Kuwait and their experiences there. It is possible that the interaction of the person and the setting as described in Chapter V accounts for the high proportion of subjects in Defense and, in another intercultural situation, more of these individuals would accept or adapt to the culture. While this study supports the usefulness of the model, it cannot be said to describe the individuals concerned in another setting.

In summary, this study does not employ cross-validity measures. Both another coder and the interviewing of another group in another setting would allow this data to be interpreted with broader implications.

\section{DIRECTIONS FOR FUTURE RESEARCH}

While researchers continue to investigate the factors of intercultural adjustment, this study suggests a different direction. Dinges (1983) called for greater emphasis on intercultural competence and this study supports that concept. It appears that the need for intercultural sensitivity as defined in this paper may vary from one setting to another. Some of the relevant factors worthy of attention are the jobs of the sojourners, the living conditions and the cultural context particular to the intercultural setting. Further studies researching the relationship between these variables and intercultural adjustment could perhaps arrive at a new definition of intercultural adaptation that integrates the above variables and the idea of intercultural sensitivity. 
A related question concerns the significance of intercultural sensitivity to the sojourner. It would be useful to compare ethnocentric and ethnorelative individuals and attempt to discover what qualitative and quantitative differences exist in their experiences. As suggested above, certain variables should be considered with the view that in different circumstances, different levels of sensitivity are, if not desirable, at least adequate. A researcher might ask what the advantage a higher level of sensitivity is to the sojourners or to the hosts. When 15 out of 15 subjects express satisfaction, all have completed contracts and most have renewed, the implication is that both sojourners and hosts are pleased, at least to a degree. The question is whether or not greater intercultural sensitivity is a goal in every situation.

The model itself deserves much more research. More information is needed to determine its usefulness in a variety of settings. A study done in the United States could be expected to draw a greater range of levels. Studies done in other intercultural conditions would aid in elucidating and enriching the data derived thus far. Future studies should pay particular attention to the distinction between Acceptance, Adaptation, and Integration and aim to discover observable characteristics of these levels. Eventually, common themes and characteristics which emerge from the research could lead to a much simplified diagnostic tool, making the model more useful in a variety of training situations.

An interesting aspect of the overseas experience has come to light in the period between the conducting of the research in Kuwait and the writing of this paper in the United States. In the year that intervened the researcher and many of these subjects lost their homes, jobs, friends and ways of life when Kuwait was invaded on August 2, 1990. The empathy for Kuwait and Kuwaitis was evident as many American residents of Kuwait reevaluated their experiences in a positive way. People who complained frequently express readiness to go back and help Kuwait rebuild. Are people truly more empathic or are they perhaps more comfortable seeing themselves as idealists instead of mercenaries? 
It would be interesting to examine whether or not these changes can be explained in terms of the model. Are the sojourners evaluating their experiences from a more ethnorelative perspective than they had while in the intercultural setting, so that this represents an increase in intercultural sensitivity? Or, perhaps appreciation for the intercultural experience is enhanced by strong feelings of marginality, or an inability to identify with the home culture. With these possibilities in mind, it would be worthwhile investigating re-entry in terms of the model.

\section{PRACTICAL APPLICATIONS}

More research needs to be done to determine the reliability and validity of the model, but its use as a descriptive tool as indicated by this study points to many applications. Multicultural and intercultural sensitivity is an advantage and a need in many fields. Few places in the United States are monocultural; "multicultural" is a commonly heard word in public education, though there are few consistent ideas of what it entails. This model provides an excellent framework for discussions and work. It does not limit itself to appreciation for a single group. Instead, development based on this model can lead to a new way of thinking, enhancing appreciation of diverse cultures and perspectives.

Where international sojourns are concerned, the study points to the importance of situational considerations. The importance of personal goals for a sojourn has perhaps been underrated. Future intercultural training could make use of these findings and stress the importance of a fit between the individual's goals for the sojourn and the likelihood of achieving those goals in a given setting.

Nevertheless, the researcher does not believe that this study indicates a need for emphasis only on situation specific orientation. All of these subjects had gained some cognitive understanding of Kuwaiti culture. In general, they were articulate about the reasons for different customs and values and the effects of these differences on daily life. 
What most of these subjects did not gain from their experiences was an appreciation for and acceptance of these differences. The result was an often disappointing and frustrating experience for many of them. Several of the subjects expressed a desire for a "better," "more intercultural" experience and were disturbed that they had not found it.

This study shows the importance of ethnorelative attitudes, particularly in increasing satisfaction with interactions. Intercultural training which limits itself to cognitive understanding or behavioral training, but fails to encourage an appreciation for difference which leads to empathy, will put limits on the experience of the participants. In both domestic and international situations, the development of strategies for encouraging ethnorelative thinking will enrich the lives of the participants. The model studied in this paper is an excellent framework for encouraging this development. 


\section{REFERENCES}

Adelman, M. \& Lustig, M. (1981). Intercultural communication problems as perceived by Saudi Arabian and American managers. International journal of intercultural relations, 5, 349 - 363.

Adler, P.S. (1977). Beyond cultural identity: Reflections upon cultural and multicultural man. In Brislin, R.W. (Ed.) Culture learning: Concepts, applications, and research. Honolulu: University of Hawaii Press.

Barna, L.M. (1976). Intercultural communication stumbling blocks. In Samovar, L. and Porter, R. (Eds.), Intercultural communication: A reader (2nd edition). Belmont: Wadsworth.

Bennett, J. (1977). Transition shock: Putting culture shock in perspective. International and intercultural communication annual, Vol. IV.

Bennett, M. (1986). Toward ethnorelativism: A developmental model of intercultural sensitivity. In Paige, M. (Ed.), Cross-cultural orientations: New conceptualizations and applications. Lanham, Maryland: University Press.

Bennett, M. (1986). A developmental approach to training for intercultural sensitivity. International journal of intercultural relations, 1(2), 179 - 196.

Bennett, M. and Bennett, J. (1977). Intercultural Workshop Facilitator Training Handbook, Portland State University.

Benson, P. (1978). Measuring cross-cultural adjustment: The problem of criteria. International journal of intercultural relations, 1978, 2(1), 21 - 37.

Bochner, S. \& Furnham, A. (1986). Culture shock. New York: Methuen, Inc.

Brein, M. \& David, K. (1971). Intercultural communications and the adjustment of the sojourner. Psychological Bulletin, 76, 215 - 230.

Brislin, R. (1981). Cross-cultural encounters: Face-to-face interaction. New York: Pergamon Press.

Church, A.T. (1982). Sojourner adjustment. Psychological Bulletin, 91(3), 540 - 572.

Cleveland, H., Mangone, G.J. \& Adams, T.G. (1960). The overseas Americans. New York: McGraw-Hill. 
Cohen, R. (1987). Problems of intercultural communication in Egyptian-American diplomatic relations. International journal of intercultural relations, 1, 29 - 47.

Dinges, N. (1983). Intercultural competence. In Landis, D. and Brislin, R. (Eds.), Handbook of intercultural training, volume 1: Issues in theory and design. New York: Pergamon.

Dooley, D. (1984). Social Research Methods. Englewood Cliffs, NJ: Prentice-Hall.

Gudykunst, W.B. \& Hammer, M.R. (1987). Strangers and hosts: An uncertainty reduction based theory of intercultural adaptation. In Gudykunst, W.B. \& Kim, Y.Y. (Eds.) Cross-cultural adaptation: Current approaches, Newbury Park: Sage Publications.

Gudykunst, W.B. \& Kim, Y.Y. (1984). Communicating with strangers: An approach to intercultural communication. Reading, Ma.: Addison-Wesley.

Gudykunst, W.B., Wiseman, R. \& Hammer, M.R. (1977). Determinants of a sojourner's satisfaction. In Ruben, B. (Ed.) Communication Yearbook 1. New Brunswick: Transaction.

Hall, E.T. \& Whyte, W.F. (1960). Intercultural communication: A guide to men of action. Human Organization, $19,5-12$.

Hall, E.T. (1976). Beyond Culture. Garden City: Doubleday and Company.

Hall, E.T. (1979). Learning the Arab's silent language. Psychology today, 13, 45 - 54

Hammer, M., Gudykunst, W.B. \& Wiseman, R. (1978). Dimensions of intercultural effectiveness: An exploratory study. International journal of intercultural relations, Winter, $382-392$.

Hoopes, D.S. (1981). Intercultural communication concepts and the psychology of intercultural experience. In Pusch, M.D. (Ed.), Multicultural education; A crosscultural training approach. Chicago: Intercultural Press.

Kealey, D.J. \& Ruben, B.D. (1983). Cross-cultural personnel selection criteria, issues, and methods. In Landis, D. and Brislin, R. (Eds.) Handbook of intercultural training, volume 1. New York: Pergamon Press.

Kelly, G.A. (1963). A theory of personality. New York: W.W. Norton \& Co.

Lamb, D. (1987). The Arabs: Journeys beyond the mirage. New York: Random House.

Lazarus, R.S. \& Folkman, S. (1984). Stress, appraisal and coping. New York: Spring Publishing Co.

Lee, E. (1980). Saudis as we, Americans as they. The bridge. Fall, 3 - 5, 32 - 35. 
Marr, P.A. (1978). Social, cultural and religious problems of adjustment for Arab students from the fertile crescent and the Gulf. In Althen, G. (Ed.) Students from the Arab world and Iran. Washington, D.C.: NAFSA.

Martin, J.N. (1987). The relationship between student sojourner perceptions of intercultural competencies and previous sojourn experience. International journal of intercultural relations. $11,337-355$.

Nader, L. (1977) Round table discussion. In Atiyeh, G.N. (Ed.) Arab and American cultures. Washington, D.C.: American Enterprise Institute for Public Policy Research.

Nydell, M.K. (1987). Understanding Arabs. Yarmouth, Maine: Intercultural Press, Inc.

Oberg, K. (1960). Culture shock: Adjustment to new cultural environment. Practical anthropology, $7,177-182$.

Ruben, B.D. (1977). Human communication and cross-cultural effectiveness. International \& intercultural communication annual, vol. IV, $98-105$.

Said, E. (1977). Round table discussion. In Atiyeh, G.N. (Ed.) Arab and American cultures. Washington, D.C.: American Enterprise Institute for Public Policy Research.

Sewell, W.H. \& Davidsen, O.M. (1956). The adjustment of Scandinavian students. Journal of social issues, 12(1), $9-19$.

Shouby, E. (1951). The influence of the Arabic language on the psychology of the Arabs. Middle East journal, $\underline{5}, 284$ - 302.

Sieveking, N.A. \& Marston, R.C. (1978). Critical selection and orientation of expatriates. Personnel Administrator, 23, (4), 19 - 23.

Singer, M.R. (1985). Culture: A perceptual approach. In Samovar, L.A. and Porter, R.E. Intercultural communication: A reader (4th edition). Belmont: Wadsworth.

Slade, S. (1981). The image of the Arab in American analysis of a poll of American attitudes. Middle East Journal, $\underline{35}$ (2), 143 - 162.

Smith, H.W. (1975). Strategies of social research. Englewood Cliffs, N.J.: Prentice-Hall, Inc.

Stening, P. (1979). Problems in cross-cultural contact: A literature review. International journal of intercultural relations, 3 , $269-314$.

Stewart, E.C. (1966). The simulation of cultural differences. Journal of Communication, $\underline{16}(4), 291-304$. 
Stewart, E.C. cited by Hoopes (1981). Intercultural communication concepts and the psychology of intercultural experience. In Pusch, M.D. (Ed.) Multicultural education: A cross-cultural training approach. Chicago: Pergamon Press.

Stoner, J.A., Aram, J.D. \& Ruben, I.M. (1972). Factors associated with effective performance in overseas work assignments. Personnel psychology, 25, 303 - 318.

Suleiman, M.W. (1973). The Arabs and the west: Communication gap. In Prosser, M.H. (Ed.) Intercommunication among nations and peoples. New York: Harper \& Row.

Taylor, S.J. \& Bogdan, R. (1984). Introduction to qualitative research methods (2nd ed.) New York: John Wiley \& Sons.

Tucker, R., Weaver, R.L. \& Berryman-Fink, C. (1981). Research in speech communication, Englewood Cliffs: Prentice-Hall.

Uehara, A. (1986). The nature of American student re-entry adjustment and perceptions of the sojourn experience. International journal of intercultural relations, 10 (4), 415 - 438 .

Useem, R.H. (1966). The American family in India. The Annals, 368, 132 - 145.

Yousef, F.S. (1974). Cross-cultural communication: Aspects of contrastive social values between North Americans and Middle Easterners. Human organization, 33, 383 387. 


\section{APPENDIX \\ THE INTERVIEW SCHEDULE}

\section{General Information}

a. Age, occupation, $M / F$, education

b. Length of time in Kuwait

c. Other overseas experience? Where? How long?

d. Languages spoken

Have you ever studied Arabic?

Yes - How well do you speak it?

How has this helped you?

No - Have you ever thought about it?

e. How much did you know about Kuwait before coming here?

Did it help at the beginning? overall?

Is Kuwait similar to or different from your expectations? How?

\section{Attitude toward Difference}

a. Do you see differences between Kuwaiti and American culture?

What? (examples)

Why do you think it's different?

How do you feel about that?

Specific categories for guidance if necessary:

1) Role of women

2) Importance of status/face

3) Sense of time

4) Effect of Islam

5) Importance of "personalism"

6) Public self/private self

7) Importance of group

b. Is there anything you prefer about Kuwaiti culture? American culture?

c. When you have a holiday, what's your first choice? Why? 


\section{Interaction}

a. How important is it to you to have good communication with Kuwaitis/Arabs?

b. How much interaction do you have with Kuwaitis/Arabs? What type?

c. Do you think you are perceived positively or negatively here as an individual? as an American?

\section{Communication Skills}

a. Have you had any problems with communication here?

(Examples) Why do you think that's a problem?

How does it make you feel?

b. What problems have remained?

Why do you think they have?

How does it make you feel?

How do you handle it?

c. Is there anything that used to be a problem but isn't now?

What has changed? What made you realize the need for a change?

How did you do this? How did you know it was effective?

d. Do you see differences between your style of communication and Kuwaiti style?

Specific categories for guidance:

1) Direct/Indirect

2) Impersonal/Personal

3) Informal/Formal

4) Understatement/Exaggeration

5) Low/High Social Desirability

Non-Verbal Communication

1) Gestures

2) Personal Space

3) Use of Eyes

How do you explain that? How does it make you feel?

What did you do about it? 
5. Stress Management

a. Do daily activities cause stress?

Yes - (examples)

Why do you think that occurs?

How do you feel about it?

What do you do about it?

No - Did they ever?

What did you do?

b. Did you experience culture shock?

Yes - What did you do about it?

6. Satisfaction

a. Do you feel successful in your role here?

Yes - In what way?

Why do you think you are successful?

Have you had to make any changes to be successful?

What? Why? Was/Is it easy or difficult?

Do you see these changes as positive or negative?

Will this affect you later?

No - What makes you think you're not?

Why do you think this happened?

What would need to be different for you to succeed?

How will this experience affect you later?

b. Are you generally able to do what is expected of you? If not, why not?

c. Why did you come to Kuwait?

Did you accomplish this?

Yes - How?

No - Why not?

d. What aspects of your life here do you really enjoy?

Do you do anything you haven't done before?

e. How does the Kuwait experience compare to your previous overseas experience?

Is one place easier/more comfortable for you than another? Why?

f. Would you like another overseas assignment?

g. Has this experience changed you?

\section{Summary}

What advice would you give to another coming to Kuwait? 